\title{
Article \\ Synergistic Interactions of Cannabidiol with Chemotherapeutic Drugs in MCF7 Cells: Mode of Interaction and Proteomics Analysis of Mechanisms
}

\author{
Muhammad A. Alsherbiny ${ }^{1,2, *}$, Deep J. Bhuyan ${ }^{1}{ }^{\complement}$, Mitchell N. Low ${ }^{1}{ }^{\oplus}$, Dennis Chang ${ }^{1}$ and Chun Guang Li ${ }^{1, *}$ \\ 1 NICM Health Research Institute, Western Sydney University, Penrith, NSW 2747, Australia; \\ D.Bhuyan@westernsydney.edu.au (D.J.B.); mitchell.low@westernsydney.edu.au (M.N.L.); \\ D.chang@westernsydney.edu.au (D.C.) \\ 2 Department of Pharmacognosy, Faculty of Pharmacy, Cairo University, Cairo 11562, Egypt \\ * Correspondence: Muhammad.alsherbiny@pharma.cu.edu.eg (M.A.A.); c.li@westernsydney.edu.au (C.G.L.)
}

Citation: Alsherbiny, M.A.; Bhuyan, D.J.; Low, M.N.; Chang, D.; Li, C.G. Synergistic Interactions of Cannabidiol with Chemotherapeutic Drugs in MCF7 Cells: Mode of Interaction and Proteomics Analysis of Mechanisms. Int. J. Mol. Sci. 2021, 22, 10103. https://doi.org/10.3390/ ijms221810103

Academic Editors: Alessio Nocentini, Wagdy M. Eldehna and

Stanislav Kalinin

Received: 27 August 2021

Accepted: 15 September 2021

Published: 18 September 2021

Publisher's Note: MDPI stays neutral with regard to jurisdictional claims in published maps and institutional affiliations.

Copyright: (c) 2021 by the authors. Licensee MDPI, Basel, Switzerland. This article is an open access article distributed under the terms and conditions of the Creative Commons Attribution (CC BY) license (https:/ / creativecommons.org/licenses/by/ $4.0 /)$.

\begin{abstract}
Cannabidiol (CBD), a nonpsychoactive phytocannabinoid, has recently emerged as a potential cytotoxic agent in addition to its ameliorative activity in chemotherapy-associated side effects. In this work, the potential interactions of CBD with docetaxel (DOC), doxorubicin (DOX), paclitaxel (PTX), vinorelbine (VIN), and 7-ethyl-10-hydroxycamptothecin (SN-38) were explored in MCF7 breast adenocarcinoma cells using different synergy quantification models. The apoptotic profiles of MCF7 cells after the treatments were assessed via flow cytometry. The molecular mechanisms of $C B D$ and the most promising combinations were investigated via label-free quantification proteomics. A strong synergy was observed across all synergy models at different molar ratios of CBD in combination with SN-38 and VIN. Intriguingly, synergy was observed for CBD with all chemotherapeutic drugs at a molar ratio of 636:1 in almost all synergy models. However, discording synergy trends warranted the validation of the selected combinations against different models. Enhanced apoptosis was observed for all synergistic CBD combinations compared to monotherapies or negative controls. A shotgun proteomics study highlighted 121 dysregulated proteins in CBDtreated MCF7 cells compared to the negative controls. We reported the inhibition of topoisomerase II $\beta$ and $\alpha$, cullin 1, V-type proton ATPase, and CDK-6 in CBD-treated MCF7 cells for the first time as additional cytotoxic mechanisms of CBD, alongside sabotaged energy production and reduced mitochondrial translation. We observed 91 significantly dysregulated proteins in MCF7 cells treated with the synergistic combination of CBD with SN-38 (CSN-38), compared to the monotherapies. Regulation of telomerase, cell cycle, topoisomerase I, EGFR1, protein metabolism, TP53 regulation of DNA repair, death receptor signalling, and RHO GTPase signalling pathways contributed to the proteome-wide synergistic molecular mechanisms of CSN-38. In conclusion, we identified significant synergistic interactions between CBD and the five important chemotherapeutic drugs and the key molecular pathways of CBD and its synergistic combination with SN-38 in MCF7 cells Further in vivo and clinical studies are warranted to evaluate the implementation of CBD-based synergistic adjuvant therapies for breast cancer.
\end{abstract}

Keywords: cannabidiol; CBD; doxorubicin; docetaxel; paclitaxel; SN-38; vinorelbine; breast cancer; synergy; apoptosis; proteomics

\section{Introduction}

Medicinal cannabis and its secondary metabolites have garnered significant attention in recent years, and have been subject to extensive research and scrutiny [1-7]. From a medicinal and pharmaceutical standpoint, nonpsychoactive phytocannabinoids — such as cannabidiol (CBD) - are the most potentially beneficial components of cannabis' chemical space [2,8]. CBD has displayed a wide range of pharmacological activities in several preclinical and clinical studies that enabled its potential application in inflamma- 
tion, cancer, cardiovascular diseases, epilepsy, and neurodegenerative and psychiatric disorders [6,9-18]. The US Food and Drug Administration (FDA) has approved Epidiolex ${ }^{\circledR \circledR}$ - a pure CBD formulation - for use in patients with Lennox-Gastaut syndrome or Dravet syndrome seizures [19]. Sativex ${ }^{\circledR \circledR}$ (2.7 mg THC and $2.5 \mathrm{mg}$ CBD per dose) has also been approved in around 30 countries for pain management in multiple sclerosis [18]. On a global scale, over 40 countries have approved medicinal marijuana/cannabis programmes. However, the Drug Enforcement Administration (DEA) has declared that CBD is a Schedule V banned substance, and its products must contain less than $0.1 \%$ $\Delta^{9}$-THC to be approved by the FDA [20]. The current legal status of CBD is neither clear nor harmonised worldwide, although there are widespread medicinal, food, or cosmetic products that contain CBD [21,22]. Intriguingly, liquid chromatography coupled with mass spectrometry enables the subnanomolar detection and quantitation of cannabinoids in different biological matrices [23].

CBD displays anticancer potential, blocking cancer initiation, progression, and invasion for various cancer types, including breast, lung, colon, prostate, brain, multiple myeloma, and skin cancers $[6,7,9]$. CDB, and the endocannabinoid system in general, have long been studied for their potential to treat cancer. Unlike the psychoactive cannabinoids, CBD has a comparatively lower affinity to both CB1 and CB2 receptors [24,25]. Nevertheless, it has been reported to act as a CB1 antagonist in murine brain tissue and vas deferens, or as an inverse agonist in human CB2 receptors [24,26]. Moreover, CBD interaction targets include 5-HT1A, GPR55, and PPAR- $\gamma$, in addition to TRPVs [27,28]. The basal respiration rate and ATP production in the gastric cancer cells were decreased by $\mathrm{CBD}$, with suppressed proliferation and tumour growth, in a murine xenograft model [29]. CBD-induced mitochondrial stress in MCF7 cells, with a modulated mitochondrial redox and dynamics, was recently reported [30]. These are all suggestive of CBD's impacts on the mitochondrial processes and energy production in cancer cells, where holistic multiomics investigations are warranted in order to understand the underlying mechanisms. Other potential targets for CBD in cancers-such as cyclin-dependent kinases (CDK) and topoisomerases-are not well explored, despite the displayed selective inhibition of topoisomerase II by CBD derivatives such as HU-331 [31]. CBD's anti-cancer mechanisms, its antiproliferative and pro-apoptotic effects, and its inhibitory effects on cancer metastasis, invasion, and migration were summarised in recent reviews $[6,7,9]$. CBD is also involved in the regulation of reactive oxygen species (ROS), endoplasmic reticulum (ER) stress, inflammation, and immunological modulation [6].

Breast cancer is the most common cancer type in women worldwide, with the highest regional incidence reported in Australia and New Zealand [32,33]. CBD was found to inhibit oestrogen-receptor-positive (ER+), -negative (ER-) or -triple-negative breast cancer cells (TNBC) in a dose-dependent manner, with relatively low $\mathrm{IC}_{50}$ values [6,34-39]. This suggests that breast cancer cells are sensitive to CBD, while non-transformed epithelial breast cells (MCF10A) are not significantly affected [10,28,39,40]. Interestingly, the administration of CBD in several clinical trials, as a single dose of 150-900 mg [41-49] or 50-1000 mg/day for up to 13 weeks [50-53], showed overall good tolerability and safety profile, with mild side effects [54]. A variety of mechanisms for CBD's antiproliferative effects have been reported, including autophagy, cell cycle arrest at the $\mathrm{G}_{1} / \mathrm{S}$ checkpoint, and apoptosis in MCF7, MDA-MB-231, and 4 T1 breast cancer cells [34,35,39,55]. Recent studies have found that the antiproliferative effect of CBD in breast cancer cells was independent of endocannabinoid receptors (to some extent), mediated primarily through ROS-induced cell death $[34,35,39,56,57]$. CBD's pro-apoptotic actions were attributed to the downregulation of mTOR, AKT, 4EBP1, and cyclin D, as well as the overexpression of PPAR- $\gamma[35,39]$, where CBD coordinated apoptosis and autophagy via Beclin-1 translocation and cleavage [39]. Furthermore, CBD inhibited the invasive and metastatic nature of aggressive TNBC breast cancer by suppressing the activation of the EGF/EGFR pathway and its downstream targets (AKT and NF- $\mathrm{KB}$ ), along with Id-1 protein downregulation by ERK and ROS $[34,36,37,55,56]$. In comparison to daily administration, CBD administered 
three times per week boosted the longevity of mice while reducing the number of metastases $[55,56]$. CDB decreased TAM recruitment by downregulating CCL3, GM-CSF, and MIP-2, resulting in an overall reduction in angiogenesis [36]. Nevertheless, more research into the anticancer mechanisms of CBD at the proteome-wide level is needed in order to comprehensively understand and decode its complicated mechanisms to encourage future clinical trials.

Based on the anticancer actions of CBD, it has been suggested that combinations of CBD and chemotherapeutic drugs may overcome cancer resilience by targeting various cancers' pathophysiological components [58,59]. Synergistic combinations offer the use of lower doses with reduced side effects and curtailed drug resistance [60,61]. For instance, CBD inhibited exosome and microvesicle release, making breast (MDA-MB-231), prostate (PC3), and hepatocellular (HEPG2) cancer cells more sensitive to cisplatin [57]. It also synergistically improved the effects of paclitaxel (PTX) and doxorubicin (DOX) in both MCF7 and MDA-MB-231 breast cancer cells [38]. Moreover, it reduced PTX-induced neurotoxicity via 5 -HT1A receptors without affecting nervous system function or chemotherapeutic efficacy [62]. CBD amended DOX-induced cardiomyopathy by regulating the cardiac mitochondrial functions in murine models [63]. Nevertheless, the synergistic interactions of CBD with chemotherapeutic drugs have not been thoroughly investigated. In particular, limited data are available on effective doses and drug interactions, and further research is required $[64,65]$. In addition, the utilisation of different synergy metrics is fundamental, as there is no consensus on a gold standard synergy quantification model [66-69].

In the present study, MCF7 cell line was selected, as it is the most studied human breast cancer cell line [70]. In addition, breast cancer chemotherapeutic agents with different modes of action - taxane microtubule stabilisers (docetaxel, paclitaxel), anthracyclines (doxorubicin), microtubule-disruptive vinca-related alkaloids (vinorelbine), and topoisomerase I inhibitors (irinotecan metabolite $=\mathrm{SN}-38$ ) —and their $\mathrm{CBD}$ combinations were studied. These chemotherapeutic agents represent the most common treatment options for stage I-IV breast cancer [71], along with other therapies, including hormonal therapy, radiotherapy, or surgery. We aimed to evaluate the synergistic interactions of CBD with chemotherapeutic drugs using different synergy quantitation metrics. The apoptotic profiles for the synergistic combinations were evaluated using flow cytometry. Furthermore, a shotgun proteomics study was conducted to decipher the proteome-level cytotoxic and synergistic mechanisms of $\mathrm{CBD}$, and the most prominent $(\mathrm{SN}-38)$ synergistic combination.

\section{Results and Discussion}

\subsection{Synergy Quantification of CBD and Standard Chemotherapeutic Drugs in MCF7 Human Breast Adenocarcinoma Cells}

Since there is no agreement on a benchmark synergy model [69] to decipher the complex interactions between drugs, the exploration of different synergy models is advised. Therefore, multiple synergy quantification metrics were implemented to gain a comprehensive understanding of the potential synergistic interactions between $\mathrm{CBD}$ and the selected chemotherapeutic drugs. The combination index (CI) model can be utilised for pairwise or higher order drug combinations in constant and non-constant ratio combinations [72]. This model was used to quantify the cytotoxic interactions against MCF7 cells after $72 \mathrm{~h}$ of treatment. The $\mathrm{CI}<1$ and $\mathrm{CI}>1$ indicate synergism and antagonism, respectively, whereas additivity is indicated by $\mathrm{CI}=1$ [72]. $\mathrm{CBD}$ and the chemotherapeutic drugs were combined in molar ratios from 1431-18:1, respectively (Table 1). CompuSyn-calculated CI values at $50,75,90,95$, and $97 \%$ inhibitory concentrations are reported in Table 1. Each combination was denoted by an ID (e.g., CDOX19), where the last two digits indicate the corresponding molar ratio of CBD and DOX, as reported in Table 1. In addition, a checkerboard assay was used to combine the chemotherapeutic drugs with $C B D$ in 1:10 and 1:2 serial dilutions, respectively (Figure 1). Therefore, synergy quantification in the Loewe, ZIP, BLISS, HSA, and $\mathrm{S}$ synergy score models along the combination sensitivity score (CSS) were scrutinised over a broader range of anticancer concentrations in order to comprehensively understand the synergistic interactions of CBD with the chemotherapeutic drugs against MCF7 cells. 
Table 1. Drug interaction analysis of cannabidiol (CBD) and the chemotherapeutic combinations in MCF7 breast cancer cells.

\begin{tabular}{|c|c|c|c|c|c|c|c|c|c|c|c|}
\hline \multirow{2}{*}{ Combo ID, Molar Ratio } & \multicolumn{5}{|c|}{ CI Values at } & \multirow{2}{*}{ CSS } & \multirow{2}{*}{$\mathbf{S}$} & \multirow{2}{*}{ ZIP } & \multirow{2}{*}{ BLISS } & \multirow{2}{*}{ LOEWE } & \multirow{2}{*}{ HSA } \\
\hline & IC50 & IC75 & IC90 & IC95 & IC97 & & & & & & \\
\hline \multicolumn{12}{|l|}{ CBD: Docetaxel } \\
\hline CDOC19, $18: 1$ & 1.23 & 1.35 & 1.64 & 2.07 & 2.60 & 35.5 & 0.33 & -11.81 & -19.12 & -6.84 & -15.76 \\
\hline CDOC28, 40:1 & 0.96 & 1.14 & 1.62 & 2.32 & 3.18 & 54.6 & 18.07 & -10.9 & -13.6 & 14.29 & -9.42 \\
\hline CDOC $37,68: 1$ & 0.70 & 0.91 & 1.46 & 2.27 & 3.27 & 41.33 & 3.96 & -9.74 & -11.35 & -8.14 & -7.08 \\
\hline CDOC $46,106: 1$ & 0.49 & 0.70 & 1.23 & 2.04 & 3.03 & 49.82 & 13.09 & -3.4 & -5.61 & -2.36 & -1.38 \\
\hline CDOC55, 159:1 & 0.45 & 0.70 & 1.35 & 2.33 & 3.54 & 52.65 & 14.33 & -3.34 & -4.58 & -2.05 & -0.8 \\
\hline CDOC64, 238:1 & 0.50 & 0.86 & 1.80 & 3.20 & 4.94 & 51.66 & 12.22 & -3.04 & -4.2 & -1.74 & -0.29 \\
\hline CDOC73, 371:1 & 0.38 & 0.72 & 1.61 & 2.95 & 4.61 & 52.44 & 13.36 & -2.36 & -3.69 & -1.35 & 0.07 \\
\hline CDOC82, 636:1 & 0.42 & 0.61 & 1.00 & 1.46 & 1.93 & 56.64 & 20.16 & 1.94 & -0.1 & 1.86 & 3.4 \\
\hline CDOC91, 1431:1 & 0.48 & 0.73 & 1.17 & 1.65 & 2.12 & 56.04 & 20.19 & 1.96 & -1.08 & 0.16 & 2.06 \\
\hline CI to DC & - & - & - & - & - & 55.50 & 18.89 & -8.41 & -7.93 & -1.46 & -0.65 \\
\hline Checkerboard & - & - & - & - & - & 72.91 & -11.77 & 1.76 & -5.07 & -4.17 & -0.66 \\
\hline $\begin{array}{l}\text { Selected dose } \\
(39.75,0.5 \mu \mathrm{M})\end{array}$ & - & - & - & - & - & - & - & 28.12 & 21.45 & 24.27 & 46.02 \\
\hline \multicolumn{12}{|l|}{ CBD: Doxorubicin } \\
\hline CDOX19, 18:1 & 1.17 & 1.16 & 1.15 & 1.14 & 1.14 & 64.78 & 46.12 & 6.07 & 4.52 & -5.24 & 1.62 \\
\hline CDOX28, 40:1 & 1.12 & 1.11 & 1.10 & 1.10 & 1.09 & 66.93 & 46.23 & 3.32 & 1.97 & -9.04 & 0 \\
\hline CDOX37, 68:1 & 1.07 & 1.06 & 1.05 & 1.05 & 1.05 & 66.94 & 43.69 & 0.18 & -1.53 & -10.92 & -2.66 \\
\hline CDOX46, 106:1 & 1.42 & 1.41 & 1.40 & 1.39 & 1.38 & 65.5 & 42.45 & 0.61 & -1.64 & -11.27 & -2.78 \\
\hline CDOX55, 159:1 & 1.34 & 1.33 & 1.32 & 1.31 & 1.31 & 24.4 & 1.7 & -13.69 & -46.05 & -55.66 & -48.18 \\
\hline CDOX64, 238:1 & 1.27 & 1.26 & 1.25 & 1.25 & 1.25 & 69.85 & 45.41 & 4.15 & 2.24 & -6.37 & 0.99 \\
\hline CDOX73, 371:1 & 1.20 & 1.19 & 1.19 & 1.18 & 1.18 & 73.33 & 48.85 & 6.67 & 5.38 & -2.87 & 4.15 \\
\hline CDOX82, 636:1 & 1.13 & 1.13 & 1.12 & 1.12 & 1.12 & 75.33 & 52.37 & 10.19 & 9.06 & 0.67 & 7.38 \\
\hline CDOX91, 1431:1 & 1.07 & 1.06 & 1.06 & 1.06 & 1.06 & 76.85 & 55.09 & 9.89 & 8.72 & -2.69 & 6.75 \\
\hline CI to DC & - & - & - & - & - & 70.24 & 53.04 & 4.96 & 4.05 & -5.43 & 2.21 \\
\hline Checkerboard & - & - & - & - & - & 54.90 & -5.31 & 1.04 & -1.05 & -9.15 & -4.31 \\
\hline $\begin{array}{l}\text { Selected dose } \\
(38.42,0.2 \mu \mathrm{M})\end{array}$ & - & - & - & - & - & - & - & 32.52 & 25.65 & 15.16 & 31.53 \\
\hline \multicolumn{12}{|l|}{ CBD: Paclitaxel } \\
\hline CPTX19, 18:1 & 1.50 & 1.61 & 1.89 & 2.35 & 2.95 & 35.94 & 0.09 & -12.32 & -20.86 & -20.59 & -19.3 \\
\hline CPTX28, 40:1 & 0.91 & 1.04 & 1.40 & 2.00 & 2.78 & 42.63 & 5.16 & -7.42 & -12.28 & -11 & -9.74 \\
\hline СРТХ37, 68:1 & 0.70 & 0.85 & 1.31 & 2.05 & 3.03 & 40.73 & 2.11 & -8.38 & -11.49 & -10.07 & -8.88 \\
\hline СРТХ46, 106:1 & 0.48 & 0.63 & 1.09 & 1.83 & 2.82 & 50.48 & 12.66 & -2.18 & -5.93 & -4.42 & -3.42 \\
\hline СРТХ55, 159:1 & 0.37 & 0.54 & 1.04 & 1.85 & 2.93 & 55.54 & 16.97 & -0.14 & -3.26 & -2.93 & -1.55 \\
\hline СРТХ64, 238:1 & 0.37 & 0.59 & 1.24 & 2.32 & 3.75 & 51.98 & 11.68 & -1.04 & -4.26 & -3.37 & -1.96 \\
\hline СРТХ73, 371:1 & 0.34 & 0.61 & 1.41 & 2.73 & 4.49 & 52.76 & 12.71 & -0.76 & -3.19 & -2.35 & -1.01 \\
\hline СРТХ82, 636:1* & 0.30 & 0.62 & 1.57 & 3.14 & 5.24 & 59.16 & 21.67 & 4.4 & 2.03 & 2.33 & 3.84 \\
\hline СРТХ91, 1431:1* & 0.33 & 0.80 & 2.21 & 4.56 & 7.68 & 59.28 & 23.01 & 3.81 & 1.2 & 1.2 & 2.66 \\
\hline CI to DC & - & - & - & - & - & 57.70 & 21.51 & -6.44 & -8.30 & -3.69 & -3.53 \\
\hline Checkerboard & - & - & - & - & - & 53.78 & -31.41 & -5.35 & -10.85 & -7.90 & -6.63 \\
\hline $\begin{array}{l}\text { Selected dose } \\
(64.6,0.1 \mu \mathrm{M})\end{array}$ & - & - & 0.68 & - & - & - & - & $\sim 2.98$ & $\sim-1.69$ & $\sim 6.1$ & $\sim 1.95$ \\
\hline \multicolumn{12}{|l|}{ CBD:SN38 } \\
\hline CSN19, 18:1 & 1.77 & 5.14 & 18.44 & 51.56 & 115.29 & 40.24 & 13.73 & -0.43 & -3.87 & -3 & -1.38 \\
\hline CSN28, 40:1 & 0.65 & 0.86 & 1.49 & 2.52 & 3.84 & 48.26 & 20.38 & 1.13 & -0.58 & 1.23 & 2.95 \\
\hline CSN37, 68:1 & 0.57 & 0.76 & 1.33 & 2.19 & 3.23 & 45.18 & 15.31 & -2.32 & -4.31 & -2.18 & -0.62 \\
\hline CSN46, 106:1 * & 0.47 & 0.59 & 0.95 & 1.44 & 1.98 & 50.63 & 21.35 & 1.96 & 0.13 & 2.04 & 3.69 \\
\hline CSN55, 159:1 & 0.47 & 0.60 & 0.94 & 1.37 & 1.82 & 50.13 & 19.75 & 1.08 & -0.83 & -0.05 & 1.7 \\
\hline CSN64, 238:1 & 0.45 & 0.60 & 0.97 & 1.40 & 1.85 & 49.6 & 18.07 & 0.23 & -1.72 & 0.05 & 1.64 \\
\hline CSN73, 371:1 ** & 0.81 & 0.66 & 0.61 & 0.60 & 0.59 & 52.98 & 21.84 & 1.83 & 0.38 & 1.99 & 3.57 \\
\hline CSN82, 636:1 ** & 0.81 & 0.71 & 0.68 & 0.67 & 0.67 & 59.38 & 29.68 & 5.05 & 3.67 & 4.45 & 6.4 \\
\hline CSN91, 1431:1 ** & 0.92 & 0.93 & 0.91 & 0.91 & 0.90 & 58.73 & 29.9 & 3.43 & 2.21 & 2.79 & 4.66 \\
\hline
\end{tabular}


Table 1. Cont.

\begin{tabular}{|c|c|c|c|c|c|c|c|c|c|c|c|}
\hline \multirow{2}{*}{ Combo ID, Molar Ratio } & \multicolumn{5}{|c|}{ CI Values at } & \multirow{2}{*}{ CSS } & \multirow{2}{*}{$S$} & \multirow{2}{*}{ ZIP } & \multirow{2}{*}{ BLISS } & \multirow{2}{*}{ LOEWE } & \multirow{2}{*}{ HSA } \\
\hline & IC50 & IC75 & IC90 & IC95 & IC97 & & & & & & \\
\hline CI to DC & - & - & - & - & - & 48.39 & 23.86 & 2.37 & 1.35 & 3.58 & 4.46 \\
\hline Checkerboard & - & - & - & - & - & 75.94 & 1.36 & 0.31 & -3.24 & -3.09 & -0.08 \\
\hline $\begin{array}{l}\text { Selected dose } \\
(42.45,0.11 \mu \mathrm{M})\end{array}$ & - & 0.66 & - & - & - & - & - & 14.55 & 23.86 & 31.38 & 33.57 \\
\hline \multicolumn{12}{|l|}{ CBD: Vinorelbine } \\
\hline CVIN19, $18: 1$ & 1.30 & 1.39 & 1.64 & 2.02 & 2.53 & 31.94 & -1.9 & -9.19 & -16.9 & -16.72 & -15.15 \\
\hline CVIN28, 40:1 & 1.03 & 1.18 & 1.58 & 2.25 & 3.12 & 37.98 & 2.98 & -8.44 & -12.37 & -12.2 & -10.12 \\
\hline CVIN37, 68:1 & 0.71 & 0.86 & 1.30 & 2.02 & 2.96 & 41.71 & 5.92 & -6.9 & -8.99 & -7.59 & -5.91 \\
\hline CVIN46, 106:1 & 0.56 & 0.74 & 1.26 & 2.12 & 3.25 & 44.84 & 9.79 & -4.31 & -6.29 & -5.35 & -3.24 \\
\hline CVIN55, 159:1 & 0.46 & 0.67 & 1.27 & 2.26 & 3.58 & 50.93 & 14.65 & -1.54 & -3.63 & -3.13 & -1.06 \\
\hline CVIN64, 238:1 & 0.45 & 0.72 & 1.52 & 2.84 & 4.58 & 49.75 & 12.98 & -2.21 & -5.08 & -3.64 & -1.84 \\
\hline CVIN73, 371:1 & 0.33 & 0.59 & 1.36 & 2.63 & 4.32 & 52.5 & 16.13 & 0.16 & -2.16 & -1.01 & 1.06 \\
\hline CVIN82, 636:1 * & 0.32 & 0.65 & 1.65 & 3.30 & 5.49 & 55.57 & 21.19 & 3.31 & 1.6 & 1.94 & 4.38 \\
\hline CVIN91, 1431:1 ** & 0.73 & 0.60 & 0.56 & 0.55 & 0.55 & 56.32 & 25.34 & 5.55 & 3.36 & 2.56 & 5.09 \\
\hline CI to DC & - & - & - & - & - & 57.45 & 23.54 & -5.89 & -6.49 & -1.64 & -0.70 \\
\hline Checkerboard & - & - & - & - & - & 56.45 & -30.43 & -1.79 & -6.39 & -4.94 & -4.07 \\
\hline $\begin{array}{l}\text { Selected dose } \\
(42.4,0.1 \mu \mathrm{M})\end{array}$ & - & $\sim 0.62-$ & - & - & - & - & - & 18.29 & 28.44 & 43.26 & 48.43 \\
\hline
\end{tabular}

$\mathrm{CI}=$ combination index; $\mathrm{CI}$ to $\mathrm{DC}=$ all combined responses from $\mathrm{CI}$ model combinations were analysed via DrugComb server; CSS = combination sensitivity score; IC = inhibitory concentration killing the corresponding percentage of MCF7 cells; HSA = highest single agent model; ZIP = zero interaction potency model; ${ }^{* *}=$ synergistic combinations in all models and inhibitory concentrations; ${ }^{*}=$ synergistic combinations in all models and most effective doses; $\sim$ = approximate score considered. Potential synergistic combinations with $\mathrm{CI}<0.7$ or synergy score > 1.5 in Loewe, HSA, ZIP, and Bliss models, or > 20 in the S model, are bold formatted. Potential effective combinations $(\mathrm{CSS}>55)$ are bold formatted. Synergy metrics listed for the selected doses are derived from CI to DC.

A strong synergy was observed in different synergy models for the CDB combined with SN-38 (CSN91, CSN82, and CSN73) and vinorelbine (CVIN91). These combinations, unlike CPTX or CDOC, showed increased synergy in the CI model, with increased cell growth inhibition (Figure 2B), which is favoured for any anticancer treatment, where any antagonistic behaviour at a low fraction affected ( $\mathrm{Fa}<0.5=50 \%$ growth inhibition) will not be alarming. CBD and SN-38 combinations with a molar ratio of 1431, 636, or 371 to 1 displayed CI values of $0.9-0.93,0.67-0.81$, and $0.60-0.81$, respectively, at the $\mathrm{IC}_{50}$ to $\mathrm{IC}_{97}$ modelled inhibitory concentrations. These combinations displayed synergistic scores in all DrugComb synergy models tested (Loewe, Bliss, HSA, ZIP, and S) when the same response data were imported to the DrugComb webserver. Moreover, CVIN91 (molar ratio of 1431:1 of CBD:VIN) showed a CI value of $0.55-0.73$, with positive synergy scores in all DrugComb models. In addition, CVIN82 displayed synergy in all DrugComb models, with synergistic $\mathrm{CI}$ values of 0.32 and 0.65 at $\mathrm{IC}_{50}$ and $\mathrm{IC}_{75}$, respectively. Interestingly, all CBD chemotherapeutic combinations at a molar ratio of 636:1 were synergistic in the Loewe, Bliss, HSA, ZIP, and S models, in agreement with the CI model at different inhibitory concentrations. Nevertheless, discording interactions were observed for the Bliss model of DOC and the CI model of DOX (Figure 2B), together with the CI values at some inhibitory concentrations for DOC, DOX, PTX, and VIN (Table 1). Both checkerboard and CI design data reanalysed in DrugComb concurred on the captured synergy of around $39 \mu \mathrm{M}$ CBD with various concentrations of different drugs (Figures 1 and 2). All of the $\mathrm{IC}_{50}$ values for the different combinations and monotherapies in the CI design are listed in Table S1. Discording CompuSyn- and GraphPad-calculated $\mathrm{IC}_{50}$ values were observed-particularly for the standard chemotherapies, despite the same data having been implemented. These findings should be considered while using only CompuSyn for synergy evaluation. 


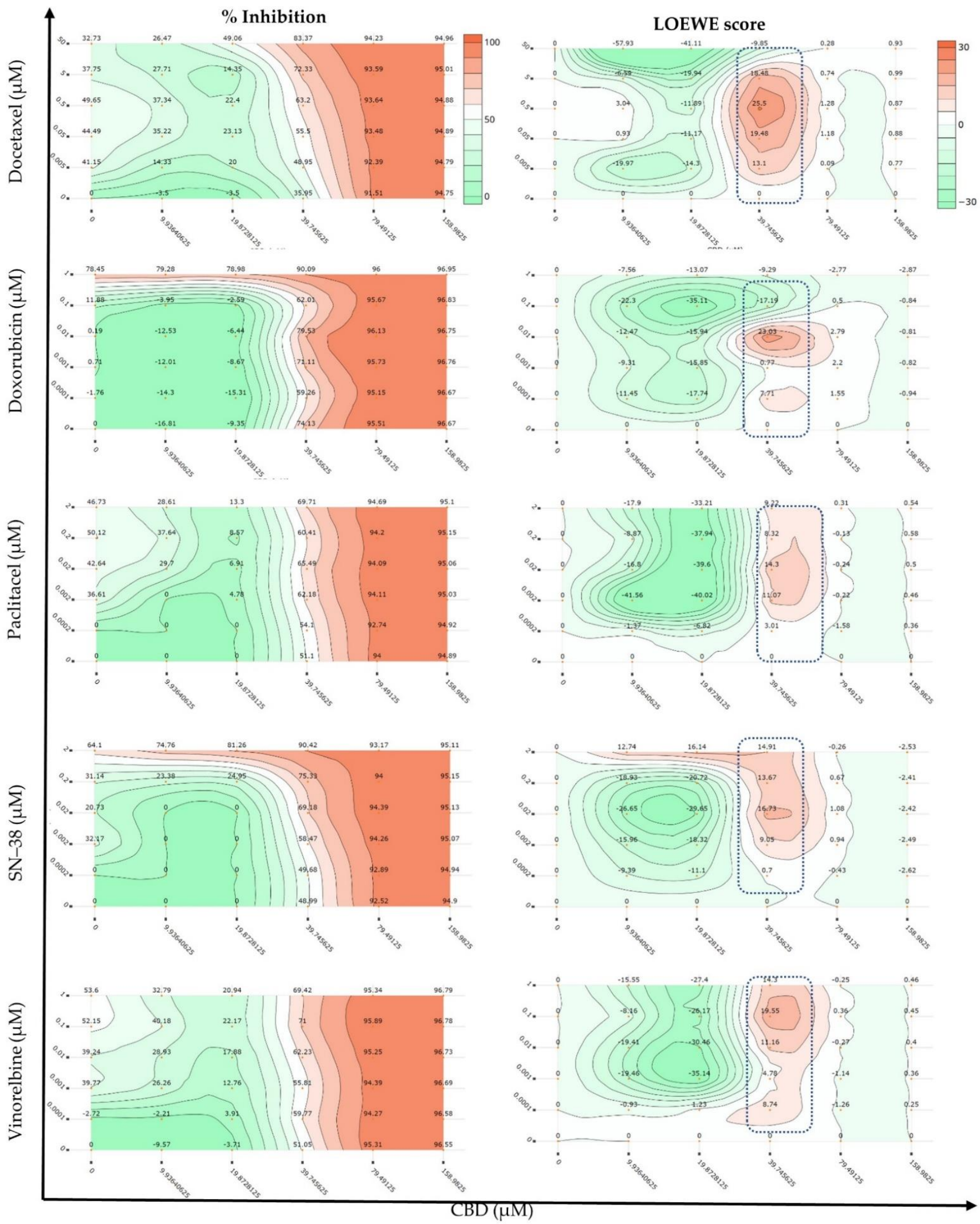

Figure 1. Dose-response and Loewe synergy quantitation of cannabidiol (CBD) combinations with the chemotherapeutic drugs against MCF7 cells in a checkerboard assay $(n=3)$. 


\section{A LOEWE score of CXYZ82}

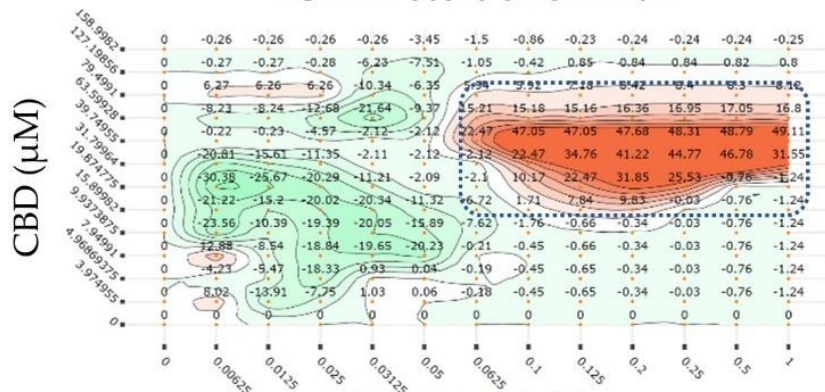

Docetaxel $(\mu \mathrm{M})$

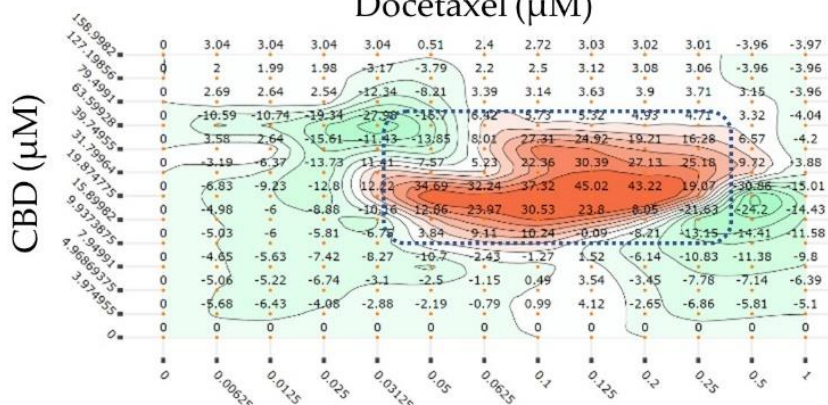

Doxorubicin $(\mu \mathrm{M})$

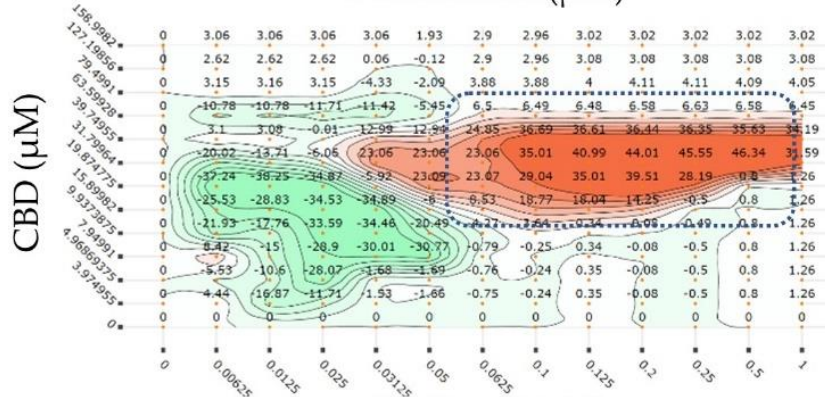

Paclitacel $(\mu \mathrm{M})$

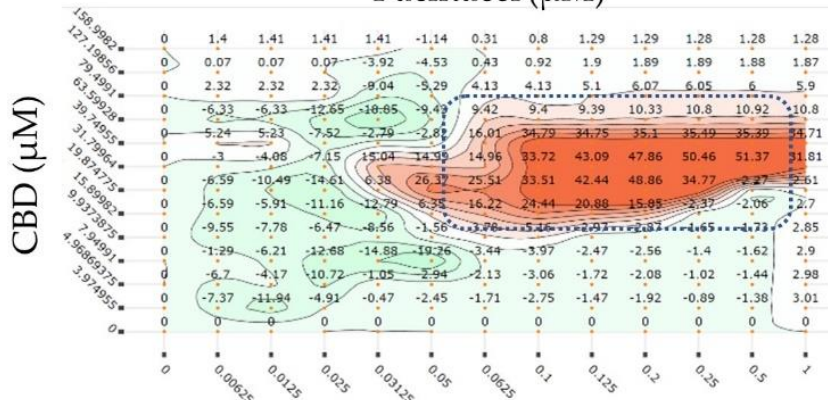

$\mathrm{SN}-38(\mu \mathrm{M})$

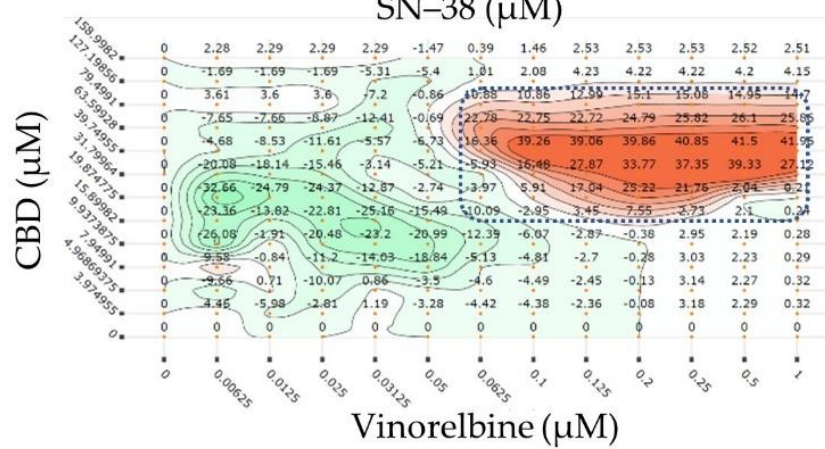

B
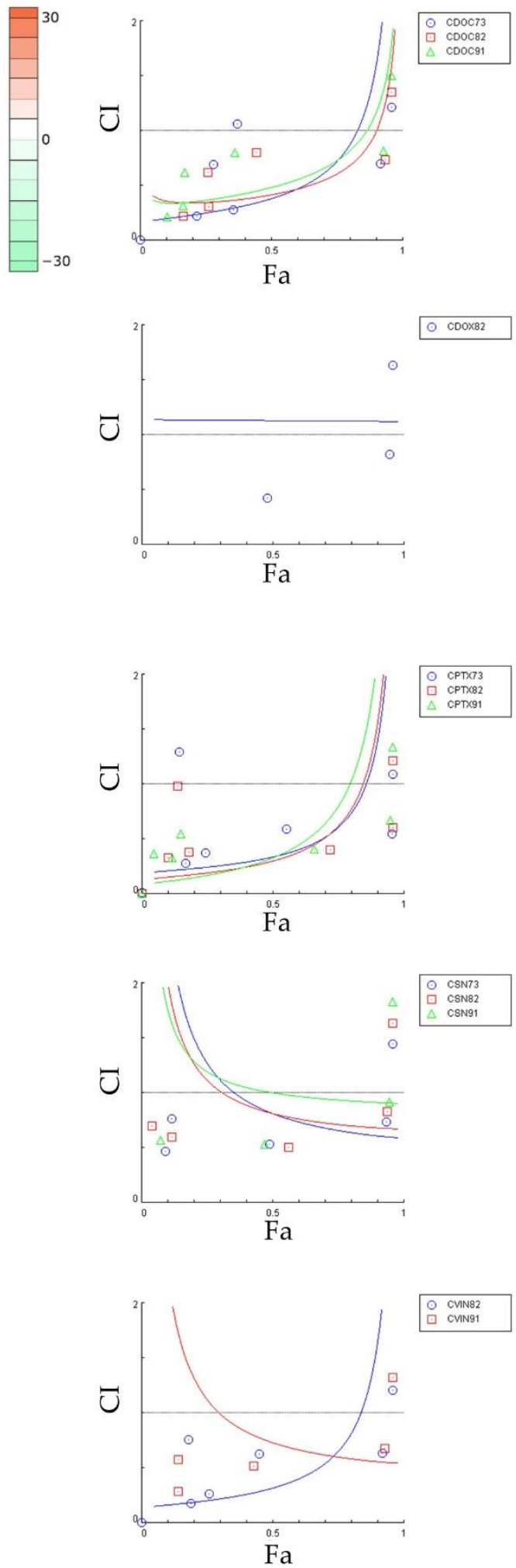

Figure 2. Most synergistic chemotherapeutic cannabidiol (CBD) combinations against MCF7 cells: (A) Loewe synergy quantitation of selected synergistic CBD combinations with standard chemotherapeutic agents (molar ratio of 636:1). (B) Combination index plots of the most synergistic combinations. Fa $=$ fraction affected ( $\%$ cell growth inhibition, where $1=100 \%$ ). 
Figure 3 and Table S2 show the Pearson and Spearman correlation matrices as linear and nonparametric rank correlation measurements, respectively, for different synergy quantification metrics and CSS. A non-significant weak correlation of the Loewe, Bliss, HSA, S, and Zip models with the CI model was indicated by the Pearson and Spearman correlation coefficients, except for the Loewe and HSA models, which were weakly and negatively correlated with the $\mathrm{CI}$ model at $\mathrm{IC}_{50}$ (Pearson $\mathrm{r}-0.45,-0.39$, respectively; $p<0.05)$. The same trend was observed for the CSS and S models' Spearman correlation with the $\mathrm{CI}$ model at high inhibitory concentrations $\left(\mathrm{IC}_{90}-\mathrm{IC} \mathrm{C}_{97}\right)$. The negative correlation displayed the different scaling, where the synergistic score of the CI model should be $<0$, and that for the DrugComb synergy metrics should be $>0$. However, moderate-tostrong Pearson and Spearman correlations were observed among the DrugComb synergy models and CSS $(0.7-0.99, p<0.05)$, except for Loewe with the CSS, S, and ZIP models (Pearson $\mathrm{r}=0.5,0.29$, and 0.52 , respectively; $p<0.05$ ) and HSA with the $S$ synergy model (Pearson $r=0.56$ ). Taken together, different synergistic interactions could have been drawn, implementing different models-particularly the CI model versus others. Notably, various synergy metrics-including Loewe, ZIP, HSA, and Bliss-displayed a moderate correlation with strong disagreement instances when calculated for the $\mathrm{O}^{\prime}$ Neil anticancer combination dataset $(22,737$ unique combinations) $[67,69,73]$. Moreover, substantial disagreements were reported when correlating synergy scores originating from different datasets [67]. Thus, the selection of synergistic doses needs to be validated against different models.

A

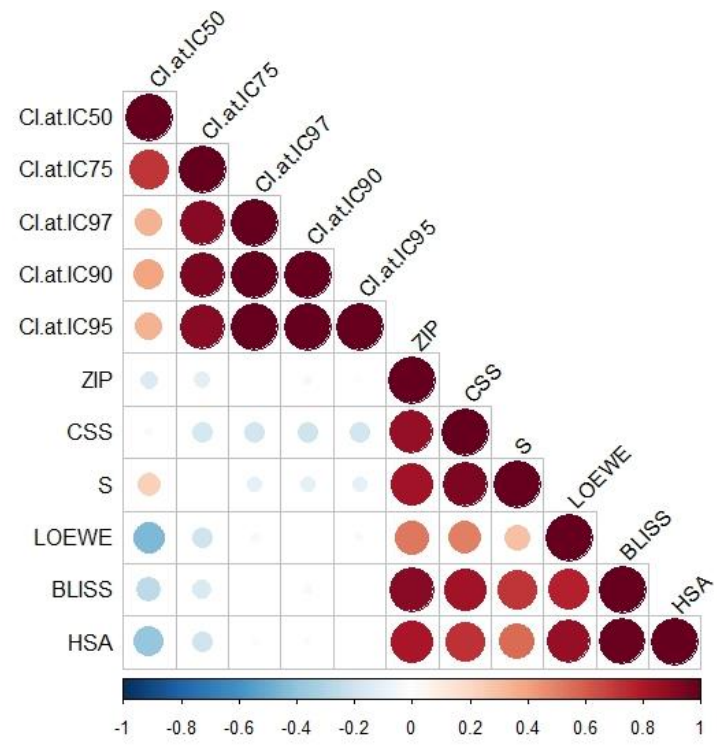

B

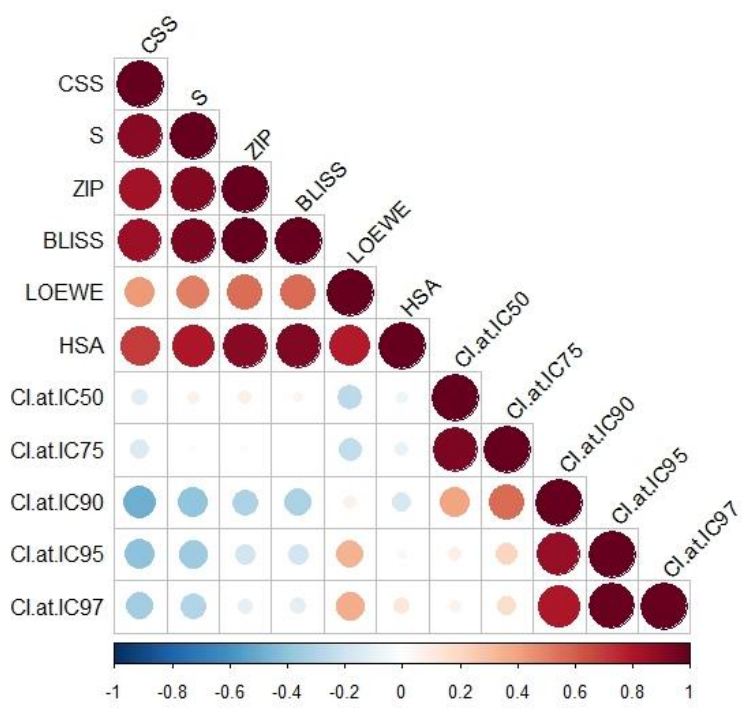

Figure 3. Correlation matrix of different synergy metrics and combination sensitivity scores (CSSs) using (A) Pearson and (B) Spearman correlation coefficients. CI = combination index derived from Chou-Talalay model; IC = inhibitory concentration killing the corresponding percentage of MCF7 cells. Colour indicates the correlation coefficient along with negative correlations in blue and positive correlations in red, with the size being directly proportional to statistical confidence based on $p$-values.

Unlike synergy, which captures the drug interactions, the combination sensitivity calculates the efficacy of the combined drugs, and its negligence may lead to biased synergistic combinations [74]. The relative $\mathrm{IC}_{50}$ value and the area under the drug combination dose-response curve were utilised to derive the CSS, which was presented as a robust metric for efficacy quantification of drug combinations [75]. Table 1 summarises the combined sensitivity scores for the combinations of CBD with the chemotherapeutic drugs tested via checkerboard assay, or upon reprocessing of CI model data via DrugComb and their aggregated data (CI to DC). Notably, promising CSS values were observed for the synergistic combinations against different study designs. The highest CSS (>70) values 
were displayed for $\mathrm{SN}-38$ and DOC combinations in the checkerboard assay, and DOX in the CI to DrugComb models. Considerably elevated CSS values were noticed for DOX combinations (CDOX19, CDOX28, CDOX37, CDOX64, and CDOX73), along with positive synergy scores in the ZIP, Bliss, and HSA synergy metrics, despite the marginally synergistic to weak antagonistic CI values (Table 1).

Previously, synergistic CBD interactions with DOX and PTX were studied against MCF7 and MDA-MB-231 cells in the CI model. A limited range of responses (total of nine doses), resulting from mixing three fixed doses of CBD with DOX $(20,1$, and $0.1 \mathrm{uM})$ and PTX $(0.5,0.1$, and $0.01 \mathrm{uM})$, were examined [38]. The molar ratio ranges from 20-2000 and 0.5-200 of CBD to 1 of PTX or DOX, respectively, were also explored in MCF7 cells [38]. Our findings are partially in agreement with the latter study in some synergy models, but we considered a broader range of responses ( 54 and 36 for our CI and checkerboard designs, respectively) in different synergy models, together with CSS calculations. Interestingly, CBD was previously reported to ameliorate DOX-induced cardiomyopathy via modulating cardiac mitochondrial functions such as complex I and complex II activities in mice $[63,76]$. In addition, CBD—or its combination with $\Delta^{9} \mathrm{THC}$-reduced the PTXinduced neuropathic pain in mice without affecting the nervous system function or PTX efficacy [62,77]. Collectively, the cardioprotective and pain relief effects of CBD, along with its synergistic interactions with DOX or PTX, warrant further studies for its potential implementation in clinical practice.

CBD has been reported to potentiate DOC-inhibitory effects in LNCaP and DU145 xenografts in vivo, and against LNCaP, 22RV1, DU-145, and PC-3 cells in vitro [78]. Interestingly, the coadministration of medicinal cannabis herbal tea did not affect the pharmacokinetics of irinotecan (and its SN-38 metabolite) and DOC [79]. Nevertheless, the potential synergistic interactions of CBD with DOC, VIN, and SN-38 have not previously been studied. The synergistic interactions of DOC, VIN, and SN-38 with CBD found in the current study require further in vivo investigations to evaluate the enhanced chemotherapeutic effects where dose reduction of chemotherapy may be expected.

In the present study, selected doses of combined CBD and chemotherapeutic drugs were validated against different models, including $\mathrm{CI}$ and DrugComb synergy metrics, with at least $90 \%$ inhibition of MCF7 cells. For DrugComb synergy models, both checkerboard design data and the combined dose responses of different combinations (CXYZ19 to CXYZ91) were considered for the selection of the synergistic doses. These synergistic doses were further utilised in the subsequent flow cytometry and shotgun proteomics studies.

\subsection{Flow Cytometric Analyses of Apoptosis in MCF7 Human Breast Adenocarcinoma Cells Using} Annexin V-CF Blue and 7-Aminoactinomycin D (7AAD)

The apoptotic profiles of MCF7 cells were evaluated using flow cytometry after $24 \mathrm{~h}$ of treatment with CBD, chemotherapeutic agents, or their combinations. The chemotherapeutic drugs (DOC, DOX, PTX, SN38, and VIN) and their most synergistic combinations with CBD were evaluated at the doses indicated in Table 1. A concurrent evaluation of apoptotic and necrotic MCF7 cells was carried out to detect whether the most synergistic combination had any enhanced apoptotic effects compared to monotherapy (Table S3). After $24 \mathrm{~h}$, significant differences in the live, early or late apoptotic, total apoptotic, and necrotic cell populations were observed in the negative controls, monotherapies, and combined treatments in pairwise comparisons via two-way ANOVA and Tukey's test for multiple comparisons correction $(p<0.05, n=3$ ) (Figure 4, Figure 5 and Figure S1, and Table S3). 


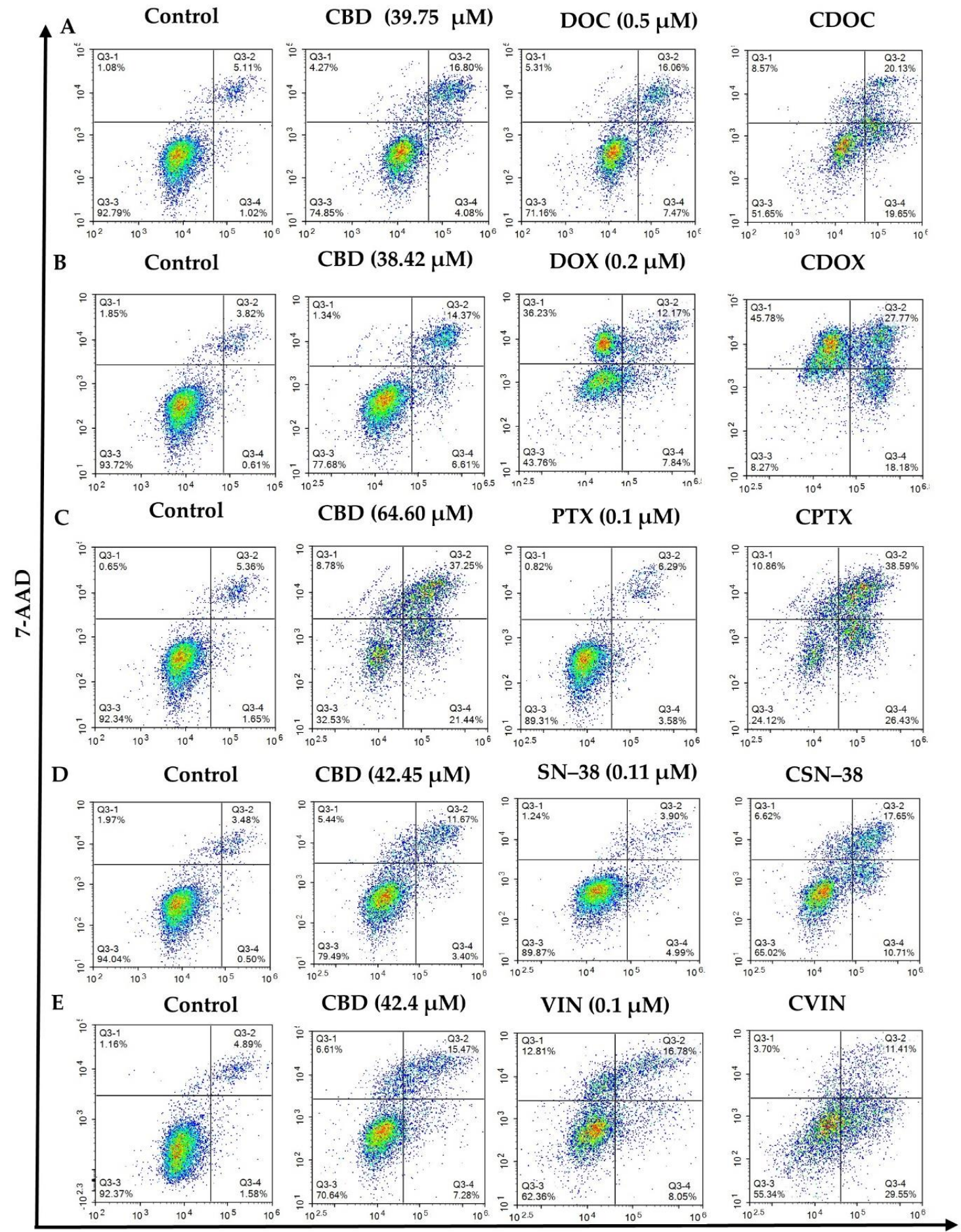

Annexin V-CF Blue

Figure 4. Flow cytometric assessment of the apoptotic profiles of MCF7 cells after $24 \mathrm{~h}$ of treatment with cannabidiol, chemotherapeutic drugs, and their synergistic combinations (A-E). The images are representative of three separate experiments. $\mathrm{CBD}=$ cannabidiol: $\mathrm{DOC}=$ docetaxel: $\mathrm{DOX}=$ doxorubicin: PTX = paclitaxel: $\mathrm{SN}-38$ : VIN = vinorelbine. (A) $\mathrm{CDOC}=\mathrm{CBD}+\mathrm{DOC},(\mathbf{B}) \mathrm{CDOX}=\mathrm{CBD}+\mathrm{DOX},(\mathbf{C}) \mathrm{CPTX}=\mathrm{CBD}+\mathrm{PTX},(\mathbf{D}) \mathrm{CSN}-38=\mathrm{CBD}+\mathrm{SN}-38,(\mathbf{E}) \mathrm{CVIN}=\mathrm{CBD}$ + VIN. Cells were treated with the monotherapies, combinations, and vehicle control ( $0.5 \%$ DMSO), and detected using antibodies against Annexin V-CF Blue and the reporter 7AAD after $24 \mathrm{~h}$ of treatment. Raw data are available in Table S3. 

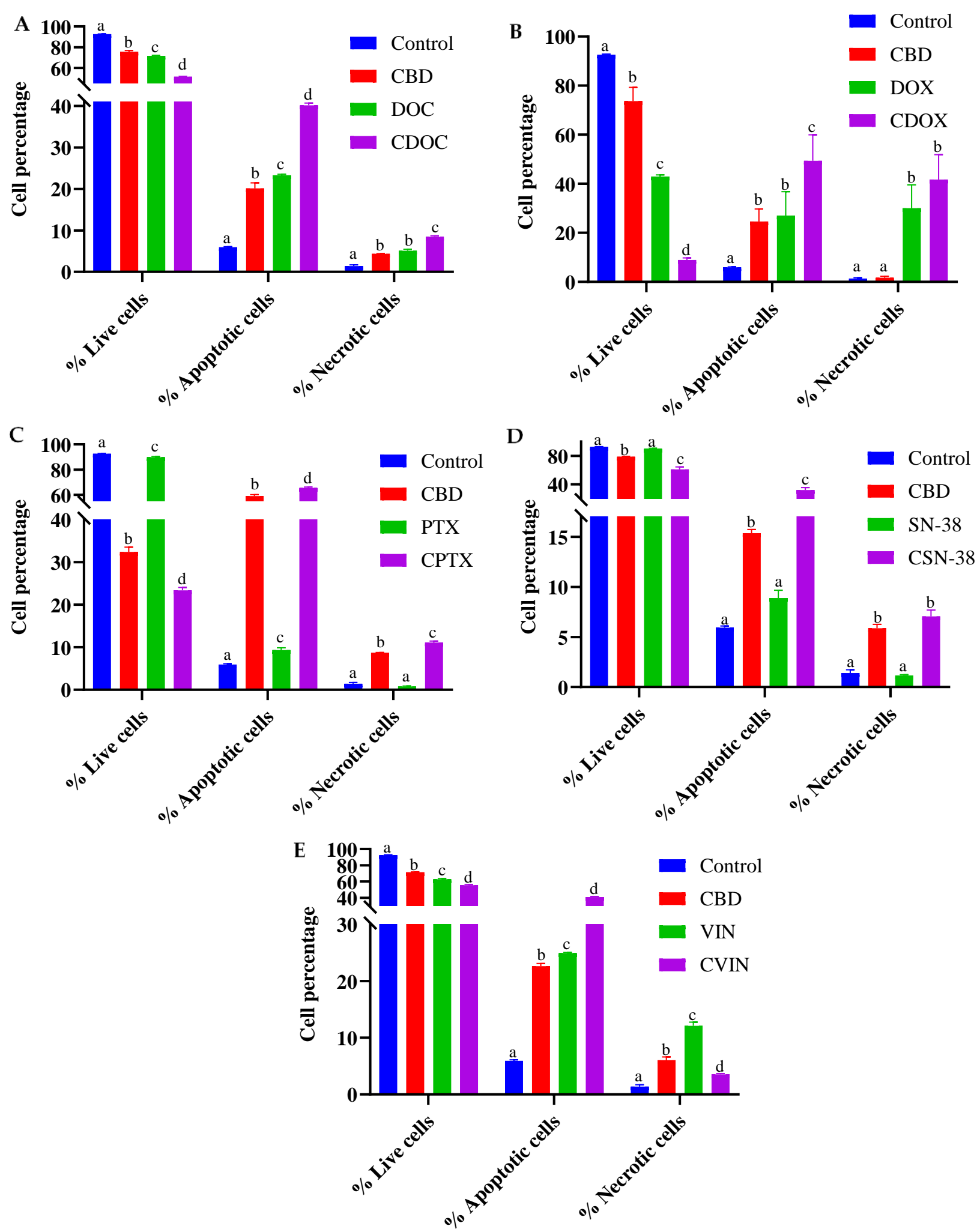

Figure 5. Cell percentage analysis of MCF7 cells after $24 \mathrm{~h}$ of treatment with cannabidiol, chemotherapeutic drugs, and their synergistic combinations (A-E). CBD = cannabidiol: $\mathrm{DOC}=$ docetaxel: $\mathrm{DOX}=$ doxorubicin: $\mathrm{PTX}=$ paclitaxel: $\mathrm{SN}-38$ : VIN = vinorelbine. (A) CDOC $=$ CBD $(39.75 \mu \mathrm{M})+\mathrm{DOC}(0.5 \mu \mathrm{M}),(\mathbf{B}) \mathrm{CDOX}=\mathrm{CBD}(38.42 \mu \mathrm{M})+\mathrm{DOX}(0.2 \mu \mathrm{M}),(\mathbf{C}) \mathrm{CPTX}=\mathrm{CBD}$ $(64.60 \mu \mathrm{M})+\operatorname{PTX}(0.1 \mu \mathrm{M}),(\mathrm{D}) \mathrm{CSN}-38=\mathrm{CBD}(42.45 \mu \mathrm{M})+\mathrm{SN}-38(0.11 \mu \mathrm{M}),(\mathrm{E}) \mathrm{CVIN}=\mathrm{CBD}(42.4 \mu \mathrm{M})+\mathrm{VIN}(0.1 \mu \mathrm{M})$. Superscript letters indicate statistical significance derived from two-way ANOVA and Tukey's multiple comparisons within the same cell group, where different letters are statistically significant at $p<0.05(n=3)$. Raw data are available in Table S3. 
CBD stimulated programmed cell death in the MDA-MB-231 breast cancer cells, with regulated crosstalk between apoptosis and autophagy [39]. In both the T-47D and MDA-MB-231 breast cancer cells, CBD treatment coordinated an interplay between PPAR- $\gamma$, mTOR, and cyclin D1 that favours apoptotic induction [35]. In the present study, CBD alone $(38.42-64.6 \mu \mathrm{M})$ significantly reduced the live population of MCF7 cells from around $92 \%$ to $78.74-32.37 \%(p<0.001)$, in a dose-dependent manner. The total apoptotic MCF7 cells were significantly increased from $5.94 \%$ to $15.38-58.94 \%$ by CBD in different concentrations $(p<0.0001)$ compared to the negative controls (Figures 4B and 5B; $p=0.0058$ for 38.42 $\mu \mathrm{M}$ CBD). However, different CBD doses significantly increased necrosis in MCF7 cells $(p<0.01)$, from $1.4 \%$ to $8.69 \%$, with the highest CBD concentration $(64.60 \mu \mathrm{M})$. Altogether, a significant 3-11-fold increase in the number of apoptotic cells was observed for different CBD doses in MCF7 cells compared to the untreated control cells, with a decreased living cell percentage and a slight increase in the number of necrotic cells $(0.29-7.29 \%)$.

Similarly, a significant reduction in the number of live cells, and increased numbers of apoptotic and necrotic cells, were observed for DOC $(0.5 \mu \mathrm{M})$ and VIN $(0.1 \mu \mathrm{M})$ as monotherapies $(p<0.0001$ in comparison to the untreated MCF7 cells; Figure 4A,E and Figure 5A,E). PTX $(0.1 \mu \mathrm{M})$ showed the same trend, except with a non-significant difference for necrotic cells $(p=0.58)$. A substantial increase in necrotic cells $(\sim 20$-fold change compared to the controls; $p<0.0001$ ) was observed for $0.2 \mu \mathrm{M}$ DOX (Figures $4 \mathrm{~B}$ and $5 \mathrm{~B}$ ). $\mathrm{SN}-38$ showed a weak decrease in the number of living cells, but its effect on apoptosis was not statistically significant at the currently selected dose of $0.11 \mu \mathrm{M}$ (Figures $4 \mathrm{D}$ and 5D). A significant decrease in the live MCF7 cell population, with enhanced apoptosis, was observed for all of the synergistic $\mathrm{CDB}$ combinations, compared to monotherapies or negative controls $(p<0.0001)$, except for apoptotic cell percentage of CDOX compared to CBD or DOX, which was slightly higher, with $p=0.0003$ and 0.001 , respectively (Figure 4, Figure 5 and Figure S1, Table S3). To this end, CBD enhanced the apoptotic activity of the studied chemotherapeutic drugs, which consequently contributed to the overall synergistic activity. For the following section, a shotgun proteomics discovery study was conducted to decipher the cytotoxic molecular mechanisms of $\mathrm{CBD}$, and its possible synergistic mechanisms with $\mathrm{SN}-38$ against MCF7 cells.

\subsection{Bottom-Up Label-Free Quantification Proteomics Study of MCF7 Cell Lysates after Treatment with $C B D$ or Its $S N-38$ Synergistic Combination}

A shotgun proteomics study of MCF7 cells treated with $42.45 \mu \mathrm{M}$ CBD, $0.11 \mu \mathrm{M}$ $\mathrm{SN}-38$, and their synergistic combination $(\mathrm{CSN}-38)$ was performed, with relative quantification, implementing the Hi-N method. The expressed proteins in CBD-treated MCF7 cells were analysed in pairwise comparisons to the control group to trace for the difference in the proteome-wide dysregulated expressions that may be associated with the cytotoxic effects of CBD. To highlight the possible CSN-38 synergistic mechanisms, the differentially expressed proteins in the combination-treated cells were analysed in pairwise comparison to the monotherapies. Among the total 3569 identified proteins, 1256 and 758 were found to be significantly different in CBD vs. Control and CSN-38 vs. monotherapies, respectively, with $p$ and $\mathrm{Q}$ values $\leq 0.05$ (Q-values are the adjusted $p$-values, and are derived based on the optimised false discovery rate (FDR) approach). Figure 6 displays the quality control metrics and overlapped proteins among different experimental groups. Decent tryptic digestion could be speculated with minimal missed cleavages, and most of the peptides were eluted in the 3rd and 4th quartiles of the LC run. In addition, the peptides with an absolute mass error of $20 \mathrm{ppm}$ were disregarded based on the mass error distribution of the identified peptides (Figure 6A). The peptide counts, unique peptide counts, $\mathrm{m} / \mathrm{z}$, confidence scores, statistics, and fold change (FC) calculations are listed in Supplementary File 2. 
A
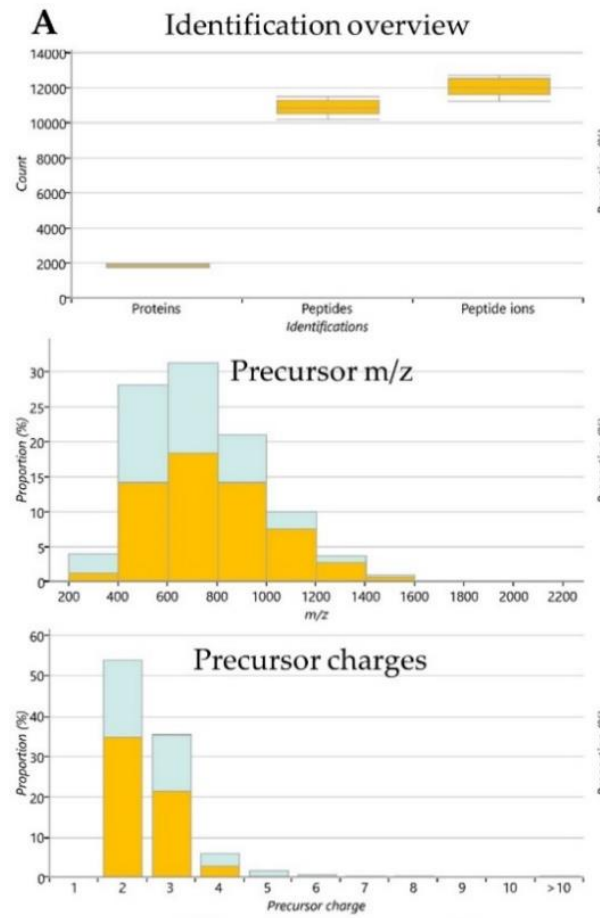

Not identified

B

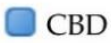

Control

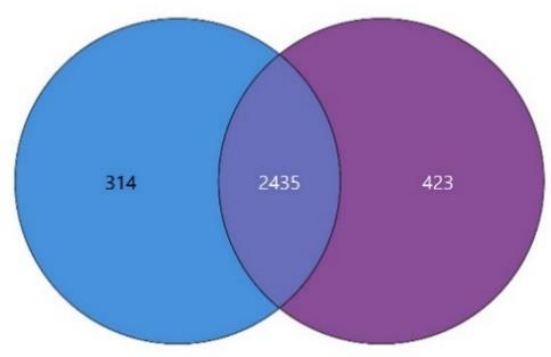

LC peak width
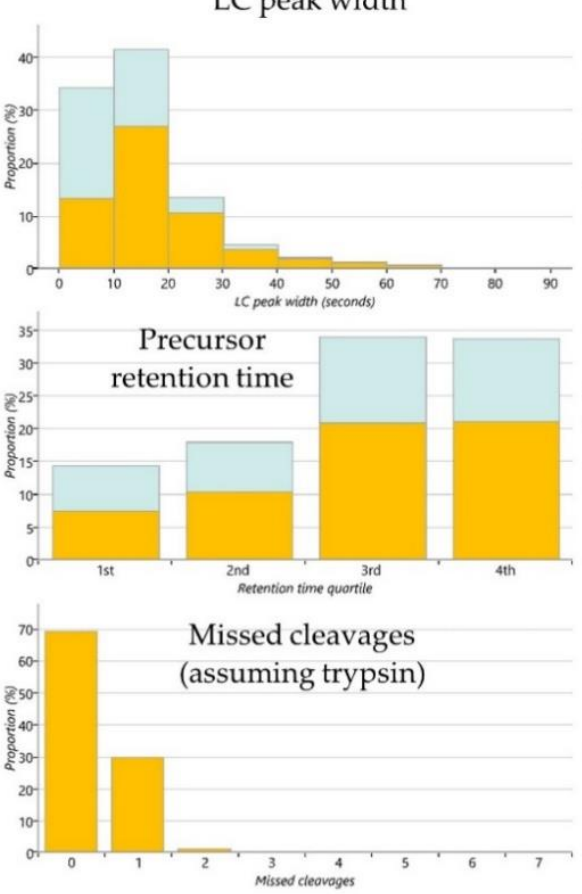

Missed cleavages (assuming trypsin)

CSN-38

Mono treatments

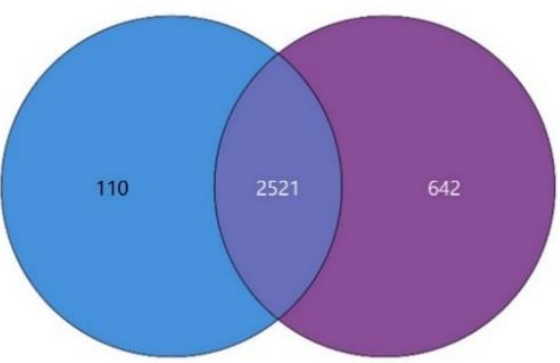

Peptide dynamic range
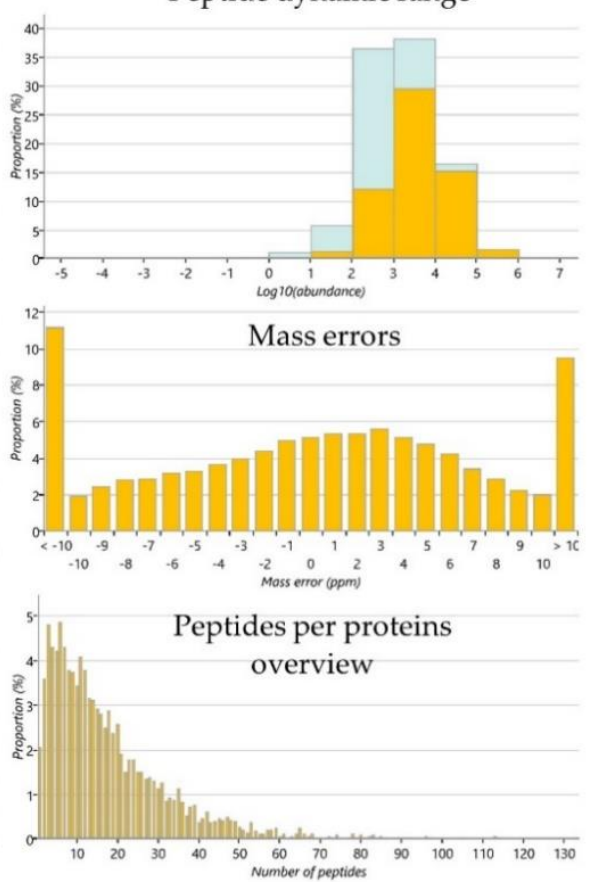

CBD

$\mathrm{SN}-38$

CNS-38

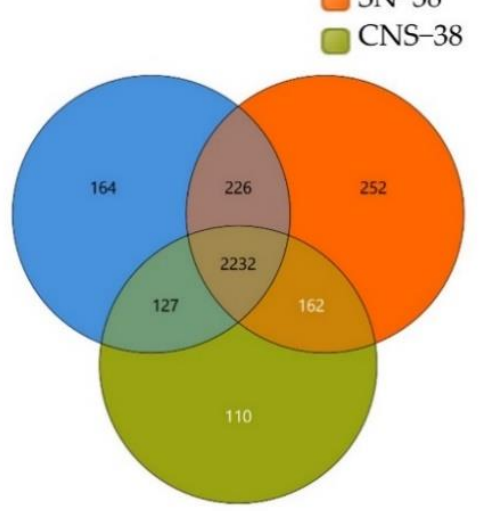

Figure 6. Label-free quantification proteomics study of cannabidiol (CBD) synergistic combination with SN-38 in MCF7 cells. (A) Overview of quality control metrics for the label-free quantification proteomics study showing peptides and protein counts, peptide charges, missed cleavage (approximately $70 \%$ of the identified peptides showed zero missed cleavage), most of the peptides eluted in the 3rd and 4th quartiles of the LC run, peak width, identified peptides per proteins, and mass errors proportions in the identified peptides. (B) Venn diagrams of the overlapped identified proteins' counts in the differently treated groups. CSN-38 = synergistic combination of CBD and SN-38; control = vehicle $(0.5 \%$ DMSO)-treated MCF7 cells.

2.3.1. Proteome-Wide Elucidation of the Cytotoxic Effects of CBD in MCF7 Cells: Pilot Shotgun Proteomics Study

The differentially expressed proteins in CBD-treated MCF7 cells, compared to the controls, were selected implementing $p$ - and Q-values of $\leq 0.01$ alongside an absolute $F C \geq 2$ (absolute $\log 2 \mathrm{FC} \geq 1$ ) cutoff. A total of 25 upregulated and 96 downregulated proteins were identified in CBD-treated cells (Tables 2 and 3, and Supplementary File 2 (CBD vs. control sheet)). These 121 dysregulated proteins represent the proteome-level variance acquired upon $C B D$ treatment. Therefore, these proteins may reflect the possible underlying mechanisms of its cytotoxic effects in MCF7 cells. 
Table 2. Significantly upregulated proteins in cannabidiol-treated MCF7 cells.

\begin{tabular}{|c|c|c|c|}
\hline Uniprot ID * & HGNC Gene ID & Protein Name & Log2 Fold Change \\
\hline P04733 & MT1F & Metallothionein-1F & 7.03 \\
\hline A0A0J9YWD4 & RIMS2 & $\begin{array}{c}\text { Regulating synaptic } \\
\text { membrane exocytosis protein } \\
2\end{array}$ & 5.80 \\
\hline Q8WX94 & NLRP7 & $\begin{array}{c}\text { NACHT_LRR and PYD } \\
\text { domains-containing protein } 7\end{array}$ & 5.75 \\
\hline P02795 & $M T 2 A$ & Metallothionein-2 & 3.78 \\
\hline Q9Y2Z9 & COQ6 & $\begin{array}{l}\text { Ubiquinone biosynthesis } \\
\text { monooxygenase COQ6 } \\
\text { Microtubule-associated }\end{array}$ & 2.60 \\
\hline A6NCE7 & $M A P 1 L C 3 B 2$ & $\begin{array}{c}\text { proteins } 1 \mathrm{~A} / 1 \mathrm{~B} \text { light chain } 3 \\
\text { beta } 2\end{array}$ & 1.68 \\
\hline E9PRY0 & EIF3M & $\begin{array}{c}\text { Eukaryotic translation } \\
\text { initiation factor } 3 \text { subunit M }\end{array}$ & 1.66 \\
\hline Q9NX24 & NHP2 & $\begin{array}{l}\text { H/ACA ribonucleoprotein } \\
\text { complex subunit } 2\end{array}$ & 1.51 \\
\hline Q5JPF3 & ANKRD36C & $\begin{array}{c}\text { Ankyrin repeat } \\
\text { domain-containing protein } \\
\text { 36C }\end{array}$ & 1.50 \\
\hline A0A0B4J1X2 & CACNA1G & $\begin{array}{l}\text { Voltage-dependent T-type } \\
\text { calcium channel subunit } \alpha-1 \mathrm{G}\end{array}$ & 1.48 \\
\hline P12645 & $B M P 3$ & Bone morphogenetic protein 3 & 1.45 \\
\hline Q9BQ39 & DDX50 & $\begin{array}{l}\text { ATP-dependent RNA helicase } \\
\text { DDX50 }\end{array}$ & 1.44 \\
\hline P08910 & ABHD2 & $\begin{array}{c}\text { Monoacylglycerol lipase } \\
\text { ABHD2 }\end{array}$ & 1.40 \\
\hline Q8TCU6 & PREX1 & $\begin{array}{l}\text { Phosphatidylinositol 3_4_5- } \\
\text { trisphosphate-dependent Rac } \\
\text { exchanger } 1 \text { protein }\end{array}$ & 1.35 \\
\hline Q3KQV9 & UAP1L1 & $\begin{array}{c}\text { UDP-N-acetylhexosamine } \\
\text { pyrophosphorylase-like } \\
\text { protein } 1\end{array}$ & 1.34 \\
\hline Q14139 & UBE4A & $\begin{array}{l}\text { Ubiquitin conjugation factor } \\
\text { E4 A }\end{array}$ & 1.26 \\
\hline M0QZQ3 & SPTBN4 & Spectrin beta chain & 1.26 \\
\hline F5GZS6 & $S L C 3 A 2$ & $\begin{array}{c}\text { 4F2 cell-surface antigen heavy } \\
\text { chain }\end{array}$ & 1.25 \\
\hline P35527 & KRT9 & Keratin_type I cytoskeletal 9 & 1.23 \\
\hline F5GX23 & PSMD9 & $\begin{array}{l}26 \mathrm{~S} \text { proteasome non-ATPase } \\
\text { regulatory subunit } 9\end{array}$ & 1.22 \\
\hline Q5XKE5 & KRT79 & $\begin{array}{c}\text { Keratin_type II cytoskeletal } \\
79\end{array}$ & 1.07 \\
\hline Q9NRV9 & HEBP1 & Heme-binding protein 1 & 1.05 \\
\hline H0YMI4 & USP3 & $\begin{array}{l}\text { Ubiquitin carboxyl-terminal } \\
\text { hydrolase }\end{array}$ & 1.01 \\
\hline B4DIG0 & $C D C 25 B$ & Protein-tyrosine-phosphatase & 1.00 \\
\hline P29992 & GNA11 & $\begin{array}{l}\text { Guanine nucleotide-binding } \\
\text { protein subunit alpha- } 11\end{array}$ & 1.00 \\
\hline
\end{tabular}

* Significantly upregulated proteins in $42.45 \mu \mathrm{M}$ CBD-treated MCF7 cells ( $p$ and Q $\leq 0.01$ alongside Progenesis QIP-calculated maximum fold change $\geq 2=\log 2$ fold change $\geq 1$ ) compared to the vehicle-treated control cells. 
Table 3. Significantly downregulated proteins in cannabidiol-treated MCF7 cells.

\begin{tabular}{|c|c|c|c|}
\hline Uniprot ID * & HGNC Gene ID & Protein Name & Log2 Fold Change \\
\hline P02538 & KRT6A & Keratin 6A & -28.33 \\
\hline E9PC85 & $L R R K 2$ & Leucine-rich repeat kinase 2 & -30.08 \\
\hline Q9BRK5 & SDF4 & $\begin{array}{l}45 \mathrm{kDa} \text { calcium-binding } \\
\text { protein }\end{array}$ & -10.86 \\
\hline P28331 & NDUFS1 & $\begin{array}{c}\text { NADH-ubiquinone } \\
\text { oxidoreductase } 75 \mathrm{kDa} \\
\text { subunit_mitochondrial }\end{array}$ & -8.44 \\
\hline K7EPA3 & TMEM161A & Transmembrane protein $161 \mathrm{~A}$ & -7.83 \\
\hline Q14249 & ENDOG & $\begin{array}{c}\text { Endonuclease } G_{-} \\
\text {mitochondrial }\end{array}$ & -7.53 \\
\hline Q9H501 & ESF1 & ESF1 homologue & -4.39 \\
\hline Q9NRY5 & FAM114A2 & Protein FAM114A2 & -4.24 \\
\hline C9J2C7 & NT5C1B-RDH14 & $\begin{array}{l}\text { NT5C1B-RDH14 readthrough } \\
\text { NADH dehydrogenase }\end{array}$ & -3.95 \\
\hline Q9NX14 & NDUFB11 & $\begin{array}{c}\text { [ubiquinone] } 1 \text { beta } \\
\text { subcomplex subunit } 11_{-} \\
\text {mitochondrial }\end{array}$ & -3.49 \\
\hline A0A3B3ISF0 & $L A R P 1 B$ & $\begin{array}{l}\text { La-related protein } 1 \mathrm{~B} \\
\text { A disintegrin and }\end{array}$ & -3.35 \\
\hline Q9UP79 & ADAMTS8 & $\begin{array}{l}\text { metalloproteinase with } \\
\text { thrombospondin motifs } 8\end{array}$ & -3.34 \\
\hline Q8IYA6 & CKAP2L & $\begin{array}{l}\text { Cytoskeleton-associated } \\
\text { protein 2-like }\end{array}$ & -3.31 \\
\hline P60602 & ROMO1 & $\begin{array}{c}\text { Reactive oxygen species } \\
\text { modulator } 1\end{array}$ & -3.26 \\
\hline P55317 & FOXA1 & $\begin{array}{l}\text { Hepatocyte nuclear factor } \\
\text { 3-alpha }\end{array}$ & -3.25 \\
\hline Q96G01 & BICD1 & $\begin{array}{c}\text { Protein bicaudal D } \\
\text { homologue } 1\end{array}$ & -3.23 \\
\hline O43291 & SPINT2 & $\begin{array}{c}\text { Kunitz-type protease inhibitor } \\
2\end{array}$ & -3.21 \\
\hline O00762 & UBE2C & $\begin{array}{c}\text { Ubiquitin-conjugating } \\
\text { enzyme E2 C }\end{array}$ & -3.04 \\
\hline O00291 & HIP1 & $\begin{array}{c}\text { Huntingtin-interacting protein } \\
1\end{array}$ & -2.83 \\
\hline Q02818 & NUCB1 & $\begin{array}{c}\text { Nucleobindin-1 } \\
\text { Neuroblast }\end{array}$ & -2.81 \\
\hline E9PJC6 & AHNAK & $\begin{array}{l}\text { differentiation-associated } \\
\text { protein AHNAK }\end{array}$ & -2.58 \\
\hline Q2TV78 & MST1L & $\begin{array}{l}\text { Putative macrophage } \\
\text { stimulating 1-like protein }\end{array}$ & -2.51 \\
\hline A0A6Q8PFY3 & FANCD2 & $\begin{array}{c}\text { Fanconi anemia group D2 } \\
\text { protein }\end{array}$ & -2.45 \\
\hline A0A0U1RR07 & SYTL2 & Synaptotagmin-like protein 2 & -2.43 \\
\hline Q8IVV2 & LOXHD1 & $\begin{array}{l}\text { Lipoxygenase homologuey } \\
\text { domain-containing protein } 1\end{array}$ & -2.31 \\
\hline Q9BUB7 & TMEM70 & $\begin{array}{c}\text { Transmembrane protein } 70_{-} \\
\text {mitochondrial }\end{array}$ & -2.28 \\
\hline Q8TCT8 & SPPL2A & $\begin{array}{l}\text { Signal peptide peptidase-like } \\
2 \mathrm{~A}\end{array}$ & -2.27 \\
\hline Q96DV4 & MRPL38 & $\begin{array}{c}\text { 39S ribosomal protein L38_ } \\
\text { mitochondrial }\end{array}$ & -2.27 \\
\hline Q9Y646 & $C P Q$ & Carboxypeptidase Q & -2.23 \\
\hline Q15036 & SNX17 & Sorting nexin-17 & -2.22 \\
\hline
\end{tabular}


Table 3. Cont.

\begin{tabular}{|c|c|c|c|}
\hline Uniprot ID * & HGNC Gene ID & Protein Name & Log2 Fold Change \\
\hline O75306 & NDUFS2 & $\begin{array}{l}\text { NADH dehydrogenase } \\
\text { [ubiquinone] iron-sulfur } \\
\text { protein 2_ mitochondrial }\end{array}$ & -2.17 \\
\hline G3V0I5 & NDUFV1 & $\begin{array}{c}\text { NADH dehydrogenase } \\
\text { [ubiquinone] flavoprotein } 1_{-} \\
\text {mitochondrial }\end{array}$ & -2.12 \\
\hline A0A590UJ21 & CUL1 & Cullin-1 & -1.97 \\
\hline Q00534 & $C D K 6$ & Cyclin-dependent kinase 6 & -1.96 \\
\hline Q9P1A6 & DLGAP2 & $\begin{array}{c}\text { Disks large-associated protein } \\
2\end{array}$ & -1.95 \\
\hline K7EJV0 & SEPTIN9 & Septin-9 & -1.92 \\
\hline E7EN73 & KIAA0319L & $\begin{array}{l}\text { Dyslexia-associated protein } \\
\text { KIAA0319-like protein }\end{array}$ & -1.92 \\
\hline C9JJ19 & MRPS34 & $\begin{array}{l}28 \mathrm{~S} \text { ribosomal protein S34_ } \\
\text { mitochondrial }\end{array}$ & -1.92 \\
\hline Q92665 & MRPS31 & $\begin{array}{l}28 \mathrm{~S} \text { ribosomal protein } \mathrm{S} 31_{-} \\
\text {mitochondrial }\end{array}$ & -1.88 \\
\hline Q96C01 & FAM136A & Protein FAM136A & -1.86 \\
\hline Q16540 & MRPL23 & $\begin{array}{l}\text { 39S ribosomal protein L23_ } \\
\text { mitochondrial }\end{array}$ & -1.83 \\
\hline A0A2R8YGD3 & RAPGEF2 & Cyclic nucleotide ras GEF & -1.81 \\
\hline G8JLA1 & RDH13 & Retinol dehydrogenase 13 & -1.80 \\
\hline P82650 & MRPS22 & $\begin{array}{l}28 \mathrm{~S} \text { ribosomal protein } \mathrm{S} 22 \\
\text { mitochondrial }\end{array}$ & -1.76 \\
\hline O00217 & NDUFS8 & $\begin{array}{l}\text { NADH dehydrogenase } \\
\text { [ubiquinone] iron-sulfur } \\
\text { protein 8_mitochondrial }\end{array}$ & -1.75 \\
\hline Q9Y2Z2 & MTO1 & $\begin{array}{l}\text { Protein MTO1 homologue } \\
\text { mitochondrial }\end{array}$ & -1.68 \\
\hline A0A0A0MRM2 & $N R A P$ & $\begin{array}{l}\text { Nebulin-related-anchoring } \\
\text { protein }\end{array}$ & -1.64 \\
\hline Q9UKX2 & MYH2 & Myosin-2 & -1.64 \\
\hline Q6X4W1 & NSMF & $\begin{array}{c}\text { NMDA receptor } \\
\text { synaptonuclear signaling and } \\
\text { neuronal migration factor }\end{array}$ & -1.62 \\
\hline O75363 & $B C A S 1$ & $\begin{array}{c}\text { Breast carcinoma-amplified } \\
\text { sequence } 1\end{array}$ & -1.62 \\
\hline O94913 & PCF11 & $\begin{array}{l}\text { Pre-mRNA cleavage complex } \\
2 \text { protein Pcf11 }\end{array}$ & -1.62 \\
\hline Q92823 & NRCAM & $\begin{array}{c}\text { Neuronal cell adhesion } \\
\text { molecule }\end{array}$ & -1.60 \\
\hline Q96EY7 & PTCD3 & $\begin{array}{c}\text { Pentatricopeptide repeat } \\
\text { domain-containing protein } 3 \text { _ } \\
\text { mitochondrial } \\
\text { Protein }\end{array}$ & -1.57 \\
\hline Q6ZXV5 & TMTC3 & $\begin{array}{c}\text { O-mannosyl-transferase } \\
\text { TMTC3 }\end{array}$ & -1.53 \\
\hline Q6IBS0 & TWF2 & Twinfilin-2 & -1.50 \\
\hline Q9NY74 & ETAA1 & $\begin{array}{c}\text { Ewing's tumour-associated } \\
\text { antigen } 1\end{array}$ & -1.50 \\
\hline Q8N961 & $A B T B 2$ & $\begin{array}{l}\text { Ankyrin repeat and BTB/POZ } \\
\text { domain-containing protein } 2\end{array}$ & -1.42 \\
\hline A0A1B0GU86 & $A C Y 1$ & $\begin{array}{l}\text { N-acyl-L-amino-acid } \\
\text { amidohydrolase }\end{array}$ & -1.42 \\
\hline P55011 & SLC12A2 & $\begin{array}{l}\text { Solute carrier family } 12 \\
\text { member } 2\end{array}$ & -1.42 \\
\hline
\end{tabular}


Table 3. Cont

\begin{tabular}{|c|c|c|c|}
\hline Uniprot ID * & HGNC Gene ID & Protein Name & Log2 Fold Change \\
\hline H7BYU6 & ZNF521 & Zinc finger protein 521 & -1.38 \\
\hline P04181 & $O A T$ & $\begin{array}{c}\text { Ornithine aminotransferase } \\
\text { mitochondrial }\end{array}$ & -1.36 \\
\hline Q8N565 & MREG & Melanoregulin & -1.33 \\
\hline Q14802 & FXYD3 & $\begin{array}{l}\text { FXYD domain-containing ion } \\
\text { transport regulator } 3\end{array}$ & -1.33 \\
\hline Q7L2E3 & DHX30 & $\begin{array}{l}\text { ATP-dependent RNA helicase } \\
\text { DHX30 }\end{array}$ & -1.32 \\
\hline Q12767 & TMEM94 & Transmembrane protein 94 & -1.31 \\
\hline Q8N0X2 & SPAG16 & $\begin{array}{l}\text { Sperm-associated antigen } 16 \\
\text { protein }\end{array}$ & -1.30 \\
\hline P14854 & COX6B1 & $\begin{array}{l}\text { Cytochrome c oxidase subunit } \\
6 \mathrm{~B} 1\end{array}$ & -1.30 \\
\hline Q92820 & GGH & Gamma-glutamyl hydrolase & -1.28 \\
\hline M0QY24 & ZNF546 & Zinc finger protein 546 & -1.26 \\
\hline Q02880 & TOP2B & DNA topoisomerase 2-beta & -1.25 \\
\hline P50579 & METAP2 & Methionine aminopeptidase 2 & -1.23 \\
\hline Q8NEZ3 & WDR19 & $\begin{array}{l}\text { WD repeat-containing protein } \\
19\end{array}$ & -1.23 \\
\hline G5E9Z9 & $L R P 2 B P$ & $\begin{array}{l}\text { LRP2 binding protein_ } \\
\text { isoform CRA_a }\end{array}$ & -1.22 \\
\hline Q8TDY2 & $R B 1 C C 1$ & $\begin{array}{l}\text { RB1-inducible coiled-coil } \\
\text { protein } 1\end{array}$ & -1.22 \\
\hline H0Y5K5 & ERGIC3 & $\begin{array}{c}\text { Endoplasmic reticulum-Golgi } \\
\text { intermediate compartment } \\
\text { protein } 3\end{array}$ & -1.20 \\
\hline Q9H869 & $Y Y 1 A P 1$ & YY1-associated protein 1 & -1.20 \\
\hline A7XYQ1 & SOBP & $\begin{array}{l}\text { Sine oculis-binding protein } \\
\text { homologue }\end{array}$ & -1.18 \\
\hline P49006 & MARCKSL1 & MARCKS-related protein & -1.18 \\
\hline H3BLV9 & SRPK1 & SRSF protein kinase 1 & -1.17 \\
\hline Q9Y487 & ATP6V0A2 & $\begin{array}{l}\text { V-type proton ATPase } 116 \\
\text { kDa subunit a2 }\end{array}$ & -1.16 \\
\hline Q9BZG8 & DPH1 & $\begin{array}{l}\text { 2-(3-amino-3- } \\
\text { carboxypropyl)histidine } \\
\text { synthase subunit } 1\end{array}$ & -1.15 \\
\hline H3BV16 & NDUFB10 & Complex I-PDSW & -1.15 \\
\hline Q99797 & MIPEP & $\begin{array}{l}\text { Mitochondrial intermediate } \\
\text { peptidase }\end{array}$ & -1.15 \\
\hline O95294 & RASAL1 & $\begin{array}{c}\text { RasGAP-activating-like } \\
\text { protein } 1\end{array}$ & -1.14 \\
\hline P23921 & $R R M 1$ & $\begin{array}{l}\text { Ribonucleoside-diphosphate } \\
\text { reductase large subunit } \\
\text { Sterile alpha motif }\end{array}$ & -1.14 \\
\hline Q8IVG5 & $S A M D 9 L$ & $\begin{array}{c}\text { domain-containing protein } \\
\text { 9-like }\end{array}$ & -1.13 \\
\hline P31350 & RRM2 & $\begin{array}{l}\text { Ribonucleoside-diphosphate } \\
\text { reductase subunit M2 }\end{array}$ & -1.13 \\
\hline Q8WVV9 & HNRNPLL & $\begin{array}{l}\text { Heterogeneous nuclear } \\
\text { ribonucleoprotein L-like }\end{array}$ & -1.08 \\
\hline A0A2R8YET2 & PRRC2C & Protein PRRC2C & -1.07 \\
\hline Q9HCM1 & RESF1 & $\begin{array}{c}\text { Retroelement silencing factor } \\
1\end{array}$ & -1.07 \\
\hline F8VWW7 & $S P R Y D 3$ & $\begin{array}{l}\text { SPRY domain-containing } \\
\text { protein } 3\end{array}$ & -1.06 \\
\hline
\end{tabular}


Table 3. Cont

\begin{tabular}{cccc}
\hline Uniprot ID * & HGNC Gene ID & Protein Name & Log2 Fold Change \\
\hline P54296 & MYOM2 & Myomesin-2 & -1.03 \\
Q86XE3 & MICU3 & Calcium uptake protein 3_ & mitochondrial \\
P49736 & MCM2 & DNA replication licensing & -1.02 \\
factor MCM2 & -1.01 \\
Q9H4E5 & RHOJ & Rho-related GTP-binding & protein RhoJ \\
Q9HAZ2 & PRDM16 & Histone-lysine & -1.01 \\
& N-methyltransferase PRDM16 & -1.00 \\
\hline
\end{tabular}

* Significantly downregulated proteins in $42.45 \mu \mathrm{M}$ CBD-treated MCF7 cells ( $p$ and $\mathrm{Q} \leq 0.01$ alongside maximum Progenesis QIP-calculated maximum fold change $\geq 2=\log 2$ fold change $\leq-1$ ) compared to the vehicle-treated control cells.

STRING [80], Reactome [81], g:Profiler [82], and IMPaLA [83] overrepresentation analyses identified a subset of downregulated proteins encoding genes such as NDUFV1, NDUFB11, NDUFB10, NDUFS1, NDUFS2, and NDUFS8. These proteins were involved in complex I biogenesis, respiratory electron transport, mitochondrial ATP synthesis, the citric acid (TCA) cycle, oxidative phosphorylation, and retrograde endocannabinoid signalling, together with $C O X 6 B$ and $A T P 6 V 0 A 2$, for all of the aforementioned processes except for retrograde endocannabinoid signalling (Table 3, Figure 7, and Supplementary File 2, ORA_Enrich. of CBD vs. C sheet). Aerobic respiration occurs exclusively in the mitochondria of the eukaryotic cells and starts with glycolysis and the TCA cycle; followed by complexes I-IV, which form the electron transport chains (ETC) within the inner membrane of the mitochondria $[84,85]$. Complex I is the largest complex of the mitochondrial ETC, offering approximately $40 \%$ contribution of the redox-driven proton pump necessary for ATP production in the mitochondria [86]. Notably, complex I is required for biosynthesis and redox regulation during cancer cell growth, resistance to cell death, and metastasis [86]. CBD's paradoxical regulatory effects on mitochondrial functions were recently reviewed in brain tissue, isolated mitochondria, and hippocampal cells [87]. CBD $(4 \mu \mathrm{M})$ was previously found to significantly undermine the basal respiration rate and ATP production in gastric cancer cells with suppressed proliferation and tumour growth in xenografted mice [29]. A similar trend was observed in the HCT116 and DLD-1 colorectal cancer cells (CRC) with Noxa- and ROS-dependent apoptosis [88].

V-ATPase inhibitors were found to facilitate the control of the tumour microenvironment, with reduced tumour acidity and metastasis, along with the prevention of chemoresistance [89].

In light of the aforementioned downregulated proteins and their involvement in the biological processes, CBD-mediated apoptosis and cytotoxicity in MCF7 cells may involve a decreased mitochondrial energy production via the downregulation of complex I- and IV-related proteins ( $\mathrm{FC}=-8.44$ to -1.15$)$. In addition, $\mathrm{CBD}$ can potentially reduce the tumour acidic microenvironment and metastasis by downregulating V-type proton ATPase $(\mathrm{FC}=-1.16)$. Here, $\mathrm{CBD}$ was reported for the first time among V-ATPase inhibitors. 


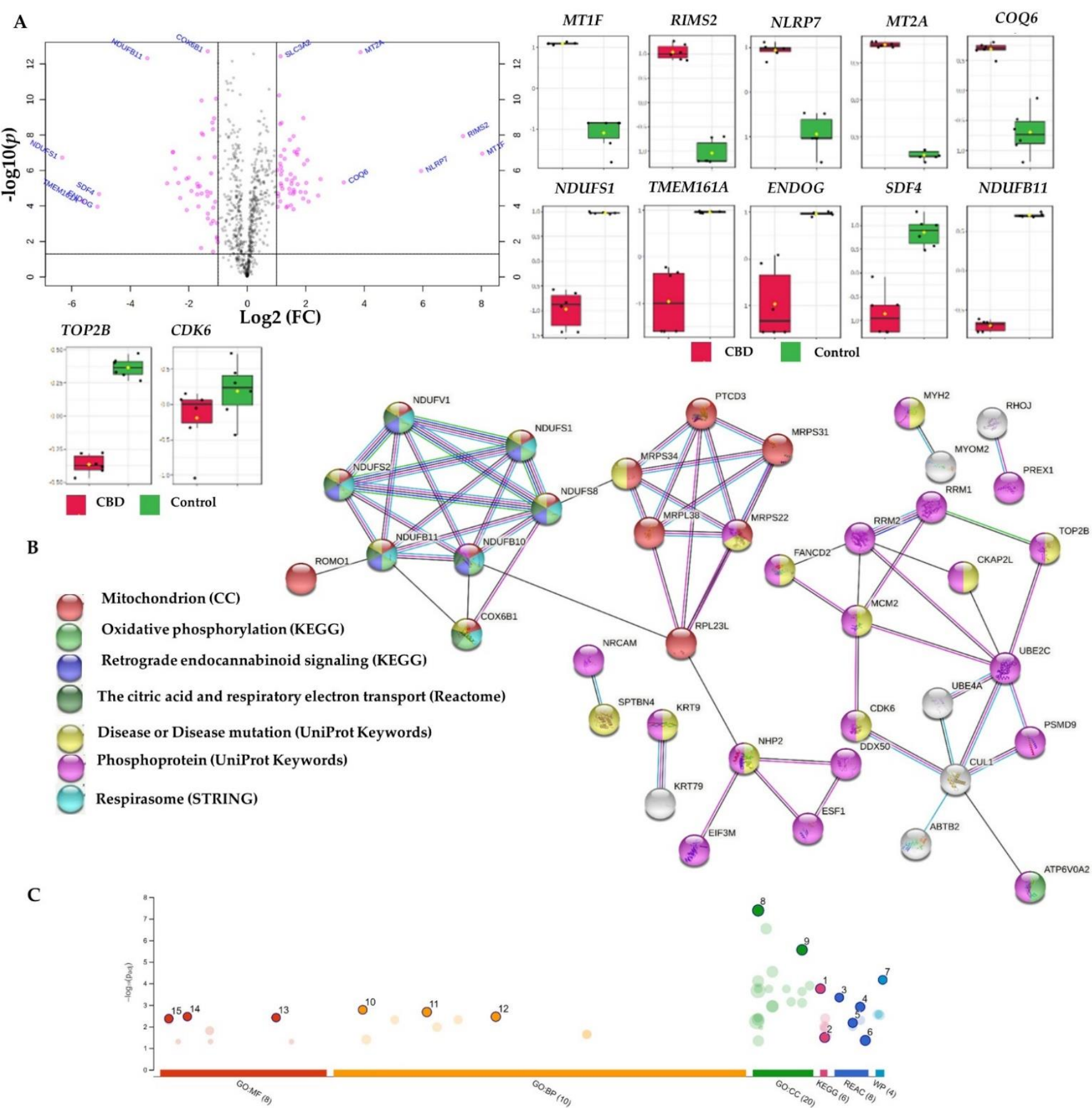

Figure 7. Differentially expressed proteins in cannabidiol (CBD)-treated MCF7 cells compared to controls, and the corresponding overrepresented pathways. (A) Volcano plot with an absolute $\log 2$ fold change $\geq 1$ and $p$-value $\leq 0.05$ cutoff, for the identified proteins in CBD-treated cells, together with selected proteins' expression summary compared to the controls. (B) STRING network of the 121 differentially expressed proteins (fold change $\geq 2 ; p$ and Q values $\leq$ 0.01 ) in the cannabidiol-treated MCF7 cells compared to the controls. The minimum required interaction score was 0.40 (medium confidence), and red, green, blue, purple, light blue, and black interaction lines indicate the presence of fusion, neighbourhood, co-occurrence, experimental, database, and co-expression evidence, respectively. The disconnected nodes were hidden in the network. (C) Overrepresented pathways using g:Profiler for the differentially expressed proteins (fold change $\geq 2 ; p$ and $\mathrm{Q}$ values $\leq 0.01)$ in the cannabidiol-treated MCF7 cells compared to the controls $(1=$ oxidative phosphorylation; $2=$ retrograde endocannabinoid signalling; $3=$ complex $\mathrm{I}$ biogenesis; $4=$ respiratory electron transport; $5=$ mitochondrial translation initiation; $6=$ the citric acid (TCA) cycle and respiratory electron transport; $7=$ mitochondrial complex I assembly model OXPHOS system; $8=$ mitochondrial inner membrane; $9=$ mitochondrial protein-containing complex; $10=$ mitochondrial electron transport; $\mathrm{NADH}$ to ubiquinone; $11=$ aerobic electron transport chain; $12=$ mitochondrial ATP synthesis-coupled electron transport; $13=\mathrm{NADH}$ dehydrogenase (quinone) activity; $14=\mathrm{NADH}$ dehydrogenase (ubiquinone) activity; $15=\mathrm{NADH}$ dehydrogenase activity). CC: cellular components; MF: molecular function; BP: biological processes; REAC: Reactome database; WP: Wiki Pathways.

In our study, CBD repressed the mitochondrial translation in MCF7 cells. Briefly, the initiation, elongation, and termination of the mitochondrial translation were also overrepresented in recruiting the 121 dysregulated proteins in different platforms (Table 3, 
Figure 7, and Supplementary File 2). The downregulated PTCD3-, MRPS22-, MRPS34-, MRPL38-, MRPS31-, and MRPL23-encoded proteins ( $F C=-2.27$ to -1.57$)$ were involved in the inhibited mitochondrial translation. Mitochondrial translation inhibition has been suggested as a therapeutic strategy for ovarian cancer [90] and human acute myeloid leukemia [91]. Altogether, CBD mediated the mitochondrial power outage alongside the inhibited mitochondrial translation in MCF7 breast cancer cells.

Expression dysregulation was observed for proteins involved in DNA synthesis, the cell cycle, mitosis checkpoints, and $\mathrm{G}_{1} / \mathrm{S}$ transition, such as the upregulated $C D C 25 B-$, NHP2-, and PSMD9-encoded proteins and the downregulated RRM2-, CUL1-, MCM2-, UBE2C-, and CDK6-encoded proteins (Tables 2 and 3, Figure 7, and Supplementary File 2). In addition, D-type cyclins and their binding partner kinases are important regulators of cell cycle progression, tumour development, and proliferation in breast cancer and normal breast epithelial cells [92]. Multiple mitogenic signalling pathways regulate and influence CDK4/ 6 and cyclin D activity, including oestrogen receptors and receptor tyrosine kinase (RTK), as well as the PI3K-AKT-mTOR or RAS-RAF-MEK-ERK pathways [92]. Of note, CDK6 knockdown was shown to overcome the abemaciclib resistance in MCF7 cells [93]. In this context, CBD-mediated inhibition of CDK-6 in MCF7 cells (FC $=-1.96)$ could be utilised to enhance the sensitivity of CDK4/6 inhibitors such as abemaciclib, palbociclib, and ribociclib for the treatment of hormone-receptor-positive breast cancer. Additionally, the downregulated cullin 1 ( $\mathrm{FC}=-1.97)$, CUL1-encoded protein may be correlated with curtailed proliferation, migration, and invasion of breast cancer [94-96]. Furthermore, CBD-downregulated minichromosome maintenance proteins (MCM), such as the DNA replication licensing factor MCM2, may elucidate the effects of CBD on replication and cell cycle development, while a recent meta-analysis postulated the overexpression of MCM2-7 as a predictive biomarker of poor cancer prognosis [97]. Similarly, a growing body of evidence supports the oncogenic potential of the ubiquitin-conjugating enzyme E2C $(U B E 2 C)$ 's overexpression in breast cancer, which is linked to the loss of BRCA1 function and induced chemical resistance in MCF7 and MDA-MB-231 cells [98]. Notably, the enhanced effects of radiation, doxorubicin, tamoxifen, and letrozole were observed in breast cancer cells upon the downregulation of UBE2C [99]. Taken together, the CBD-mediated downregulation of MCM2- and UBE2C-encoded proteins contributed to the overall cytotoxicity of $\mathrm{CBD}$, along with the suppressed proliferation, migration, and invasion via the declined expression of cyclin-dependent kinase 6 (CDK6) and cullin 1 in MCF7 cells.

Topoisomerase II (TOP2) inhibitors are potent chemotherapeutic drugs that regulate DNA replication [100]. DNA Topoisomerase II $\beta$ and $\alpha$ (TOP2B and TOP2A) were significantly downregulated in CBD-treated MCF7 cells compared to the controls, with FC $=-1.25$ and -0.72 , respectively (Table 3 and Supplementary File 2). Previously, CBD derivatives such as HU-331 displayed selective inhibition to topoisomerase II isoforms via non-competitive inhibition of their ATPase activity [31]. Here, we report the inhibition of TOP2 isoforms in CBD-treated MCF7 cells for the first time, as an additional cytotoxic mechanism, along with the aforementioned downregulation of CDK-6-, MCM2-, and $U B E 2 C$-encoded proteins. In addition, the mitochondria-related mechanisms were underlined, including sabotaged energy production and mitochondrial translation.

2.3.2. Proteome-Wide Elucidation of Synergistic Mechanisms of SN-38 Synergistic Combination with CBD in MCF7 Cells: Pilot Shotgun Proteomics Study

The differentially expressed proteins in the synergistic CBD and $\mathrm{SN}-38$ combinationtreated cells, compared to the monotherapies, were selected implementing $p$ - and Qvalues of $\leq 0.01$ alongside a maximum FC $\geq 2$ (absolute $\log 2 \mathrm{FC} \geq 1$ ) cutoff. A total of 5 upregulated and 31 downregulated proteins were identified in CBD-treated cells. These 36 dysregulated proteins represent the proteome-level variance acquired upon CSN-38 treatment (Table 4). Therefore, they may reflect the possible underlying synergistic mechanisms of action against MCF7 breast adenocarcinoma cells. Relaxed $p$ - and Q-values of $\leq 0.05$, together with the same FC cutoff, identified 91 dysregulated proteins recruited 
in further pathway analyses, where no significant pathway enrichment was identified implementing the 36 most significant proteins.

Table 4. Significantly downregulated proteins in CSN38-treated MCF7 cells compared to the monotherapies.

\begin{tabular}{|c|c|c|c|}
\hline UniProt ID & HGNC Gene ID & Description & Log2 Fold Change * \\
\hline \multicolumn{4}{|c|}{ Downregulated proteins } \\
\hline O75363 & $B C A S 1$ & $\begin{array}{c}\text { Breast carcinoma-amplified sequence } \\
1\end{array}$ & -27.75 \\
\hline Q9NVH1 & DNAJC11 & $\begin{array}{l}\text { DnaJ homologue subfamily } \mathrm{C} \text { member } \\
11\end{array}$ & -24.68 \\
\hline O00762 & $U B E 2 C$ & Ubiquitin-conjugating enzyme E2 C & -4.84 \\
\hline O94913 & PCF11 & $\begin{array}{l}\text { Pre-mRNA cleavage complex } 2 \\
\text { protein Pcf11 }\end{array}$ & -4.32 \\
\hline $\begin{array}{l}\text { A0A1B0GU86 } \\
\text { A0A2R8YGD3 }\end{array}$ & $\begin{array}{c}\text { ACY1 } \\
\text { RAPGEF2 }\end{array}$ & $\begin{array}{l}\mathrm{N} \text {-acyl-L-amino-acid amidohydrolase } \\
\text { Cyclic nucleotide ras GEF }\end{array}$ & $\begin{array}{l}-4.16 \\
-2.48\end{array}$ \\
\hline Q9P1V8 & SAMD15 & $\begin{array}{l}\text { Sterile alpha motif domain-containing } \\
\text { protein } 15\end{array}$ & -2.44 \\
\hline Q8TDI0 & CHD5 & $\begin{array}{c}\text { Chromodomain-helicase-DNA- } \\
\text { binding protein } \\
5\end{array}$ & -2.42 \\
\hline K7ER88 & $A C A A 2$ & $\begin{array}{l}\text { 3-Ketoacyl-CoA thiolase } \\
\text { mitochondrial (Fragment) }\end{array}$ & -2.05 \\
\hline P20701 & ITGAL & Integrin alpha-L & -2.01 \\
\hline A0A0D9SG95 & CCT7 & T-complex protein 1 subunit eta & -1.78 \\
\hline P03952 & KLKB1 & Plasma kallikrein & -1.72 \\
\hline Q92823 & NRCAM & Neuronal cell adhesion molecule & -1.63 \\
\hline O75582 & RPS6KA5 & \multirow{2}{*}{$\begin{array}{l}\text { Ribosomal protein S6 kinase alpha-5 } \\
\text { Endosome/lysosome-associated } \\
\text { apoptosis and autophagy regulator } 1\end{array}$} & -1.56 \\
\hline Q6UXG2 & ELAPOR1 & & -1.56 \\
\hline Q5H9M0 & PWWP3B & $\begin{array}{l}\text { PWWP domain-containing } \\
\text { DNA repair factor 3B }\end{array}$ & -1.47 \\
\hline P55199 & ELL & $\begin{array}{l}\text { RNA polymerase II elongation factor } \\
\text { ELL }\end{array}$ & -1.46 \\
\hline Q9NPB8 & GPCPD1 & $\begin{array}{l}\text { Glycerophosphocholine } \\
\text { phosphodiesterase GPCPD1 }\end{array}$ & -1.46 \\
\hline Q2TV78 & MST1L & $\begin{array}{l}\text { Putative macrophage stimulating } \\
\text { 1-like protein }\end{array}$ & -1.42 \\
\hline A0A0U1RQX8 & $C B L$ & E3 ubiquitin-protein ligase CBL & -1.35 \\
\hline Q6P4H8 & ATPSCKMT & $\begin{array}{l}\text { ATP synthase subunit } C \text { lysine } \\
\text { N-methyltransferase }\end{array}$ & -1.34 \\
\hline O14513 & NCKAP5 & Nck-associated protein 5 & -1.33 \\
\hline Q8WVV9 & HNRNPLL & $\begin{array}{l}\text { Heterogeneous nuclear } \\
\text { ribonucleoprotein L-like }\end{array}$ & -1.32 \\
\hline A0A2R8Y5P9 & SHROOM3 & Protein Shroom3 & -1.22 \\
\hline $\mathrm{O} 43303$ & ССР110 & $\begin{array}{c}\text { Centriolar coiled-coil protein of } 110 \\
\text { kDa }\end{array}$ & -1.18 \\
\hline Q9C091 & GREB1L & GREB1-like protein & -1.13 \\
\hline Q9BQ52 & $E L A C 2$ & $\begin{array}{c}\text { Zinc phosphodiesterase ELAC protein } \\
2\end{array}$ & -1.12 \\
\hline A0A075B757 & NBPF14 & $\begin{array}{c}\text { Neuroblastoma breakpoint family } \\
\text { member } 14\end{array}$ & -1.11 \\
\hline O14497 & ARID1A & $\begin{array}{l}\text { AT-rich interactive domain-containing } \\
\text { protein } 1 \mathrm{~A}\end{array}$ & -1.10 \\
\hline Q96C90 & PPP1R14B & $\begin{array}{c}\text { Protein phosphatase } 1 \text { regulatory } \\
\text { subunit } 14 \mathrm{~B}\end{array}$ & -1.04 \\
\hline \multirow[t]{2}{*}{ Q6IEG0 } & SNRNP48 & $\begin{array}{l}\mathrm{U} 11 / \mathrm{U} 12 \text { small nuclear } \\
\text { ribonucleoprotein } 48 \mathrm{kDa} \text { protein }\end{array}$ & -1.00 \\
\hline & \multicolumn{2}{|c|}{ Upregulated proteins } & \\
\hline $\begin{array}{l}\text { O94973 } \\
\text { O14949 }\end{array}$ & $\begin{array}{l}A P 2 A 2 \\
\text { UQCRQ }\end{array}$ & \multirow{4}{*}{$\begin{array}{c}\text { AP-2 complex subunit alpha-2 } \\
\text { Cytochrome b-c1 complex subunit } 8 \\
\text { Mitogen-activated protein kinase } 15 \\
\text { (Fragment) } \\
\text { ATPase family } \\
\text { AAA domain-containing protein 3B } \\
\text { 4-Trimethylaminobutyraldehyde } \\
\text { dehydrogenase }\end{array}$} & $\begin{array}{l}1.20 \\
1.11\end{array}$ \\
\hline A0A1C7CYZ1 & MAPK15 & & 1.10 \\
\hline Q5T9A4 & ATAD3B & & 1.03 \\
\hline P49189 & $A L D H 9 A 1$ & & 1.01 \\
\hline
\end{tabular}

$*: p$ and $\mathrm{Q} \leq 0.01$ alongside maximum Progenesis QIP-calculated fold change $\geq 2$ (absolute log2 fold change $\geq 1$ ), compared to the monotherapies (CBD and SN-38); CSN38: the synergistic combination of $42.45 \mu \mathrm{M}$ cannabidiol and $0.11 \mu \mathrm{M} \mathrm{SN}-38$.

A subset of downregulated proteins encoding genes such as CCT7, ATM, and MAP3K4, alongside the overexpressed MAPK15 involved in the positive regulation of telomere maintenance by telomerase, was identified upon the recruitment of the 91 dysregulated proteins (Supplementary File 2, CSN38 vs. Monotherapies sheet) in STRING [80] and g:Profiler [82] overrepresentation analyses (Figure 8). 

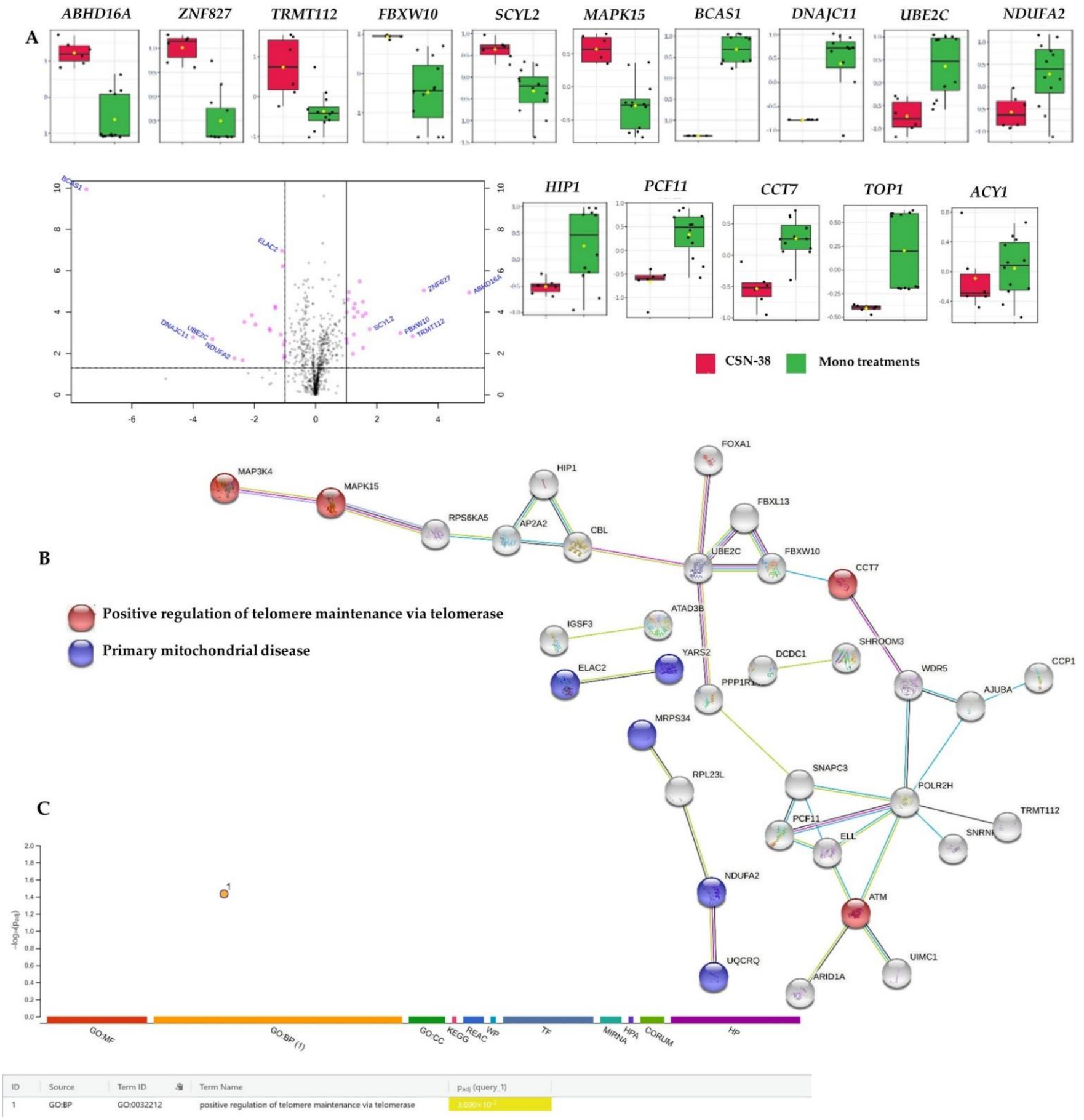

Figure 8. Differentially expressed proteins in synergistic CBD and SN-38 combination-treated MCF7 cells (CSN-38) compared to the monotherapies, and the corresponding overrepresented pathways. (A) Volcano plot with an absolute log2 fold change $\geq 1$ and $p$-value $\leq 0.05$ cutoff of the identified proteins in the CSN-38-treated cells, together with the selected proteins' expression summary compared to the monotherapies. (B) STRING network of the 91 differentially expressed proteins (fold change $\geq 2 ; p$ and $Q$ values $\leq 0.05$ ). The minimum required interaction score was 0.40 (medium confidence), and red, green, blue, purple, light blue, and black interaction lines indicate the presence of fusion, neighbourhood, cooccurrence, experimental, database, and co-expression evidence, respectively. The disconnected nodes were hidden in the network. (C) Overrepresented pathways using g:Profiler for the differentially expressed proteins (fold change $\geq 2 ; p$ and $Q$ values $\leq 0.05)$. 
We observed overexpressed chaperonin-containing TCP-1s (CCTs), such as CCT7, which was shown to be involved in breast cancer progression, associated with poor overall survival in breast cancer patients, and was recently speculated as a potential breast cancer therapeutic target and valuable prognostic marker [101]. In addition, ATM serine/threonine kinase encoded by ATM is involved in DNA repair, cell cycle arrest, and apoptosis as activated and recruited upon DNA double-strand breaks (DSBs) [102,103]. ATM gene mutations result in ataxia-telangiectasia, where disrupted recognition and repairs of DNA double-strand breaks (DSBs) take place, with increased risk of cancer [104,105]. CSN-38 significantly downregulated both T-complex protein 1 subunit eta (CCT7) and ATM in MCF7 cells ( -1.78 and -2.84 FC, respectively) compared to the monotherapies, where impaired DNA DSB repairs and tumour progression could be anticipated through the synergism of CBD and SN-38.

Mitogen-activated protein kinase 4 (MAP3K4) was also downregulated and was highlighted as a potential radiation response biomarker in both post- and preoperative settings in breast cancer patients [106]. Unlike healthy tissue, tumours increase extracellular acidification as cancer cells ferment glucose with increased lactate production, and maintain the same level of mitochondrial respiration even in the presence of oxygen, which was hypothesized by Otto Warburg as a hallmark of cancer $[107,108]$. Interestingly, the MAP3K4 downregulation inhibited the Warburg effect by regulating lactate secretion and lactate receptor expression through the HER2/HER3 signalling pathways in MCF7 cells [109]. In our study, CSN-38 significantly decreased the expression of MAP3K4 (FC -1.15, $\mathrm{Q}=0.025$; Supplementary File 2, CSN38 vs. Monotherapies sheet), which might inhibit the migration and extracellular acidity of MCF7 cells. In addition to MAP3K4, MAPK15 was also involved in the MAPK signalling pathway and was overexpressed in the CSN38treated cells compared to the monotherapies. Increased migration of breast and lung cancer cells was reported earlier upon the downregulation of MAPK15 (alias ERK8), which acts as a negative regulator of cell migration and $\mathrm{O}$-glycosylation of $\mathrm{N}$-acetylgalactosamine (GalNAc) [110]. O-GalNAc glycosylation in the endoplasmic reticulum was reported as a driving mechanism of cancer invasiveness [111]. Based on the current findings, the CSN-38 treatment might inhibit the invasiveness and migration of MCF7 cells by increasing MAPK15 expression (FC 1.1).

Several proteins involved in the cell cycle, EGFR1, metabolism of proteins, TP53 regulation of DNA repair, death receptor signalling, and RHO GTPase signalling pathways were significantly over-represented or enriched $(p \leq 0.05)$ in IMPaLA or Reactome analyses upon recruiting the 91 dysregulated proteins in the combination-treated MCF7 cells. However, a high false discovery rate or $Q$ value $\geq 0.05$ was observed for these pathways (Supplementary File 2, ORA_Enrich of CSN38 vs. Monotherapies sheet). All of the involved proteins identified in Reactome-enriched pathways were downregulated (encoded by ELL, ATM, POLR2H, PCF11, SNAPC3, ABR, PREX1, IRAK1, SPPL2A, NGEF, ITGAL, KLKB1, TMEM87A, ELAC2, UBE2C, ARID1A, NUP93, WDR5, ZNF546, ZNF521, CCT7, ACY1, AJUBA, NRCAM, and CBL), except for FBXW10-encoded protein, which was overexpressed.

The most downregulated proteins in the combination-treated MCF7 cells were breast carcinoma-amplified sequence 1 , DnaJ homologue subfamily $\mathrm{C}$ member $11, \mathrm{NADH}$ : ubiquinone oxidoreductase subunit A2, and ubiquitin-conjugating enzyme E2 C (FC $-27.75,-24.86,-5.01$, and -4.84 , respectively), compared to the monotherapies. The synergistic combination significantly diminished the expression of breast carcinoma-amplified sequence 1 -a breast cancer oncogenic protein that is linked to mammary tumourigenesis [112]. Complex I-related proteins (NDUFA2) and UBE2C-encoded protein are discussed in Section 2.3.1. DnaJ homologue subfamily $C$ member 11 is a heat shock protein, recently found to be upregulated in breast cancers such as basal, luminal B, and HER2 breast cancer subtypes, and downregulated in other tumour types; however, its functional role in breast cancer has not yet been deciphered [113,114]. 
Three downregulated proteins encoded by ABR, PREX1, and NGEF (FC $-1.84,-1.06$ and -1.0 , respectively) were involved in death receptor signalling, p75NTR receptormediated signalling (NGFR), and cell death signalling via NRAGE, NRIF, and NADE, as identified in Reactome enrichment analysis ( $p$-values $2.82 \times 10^{-3}, 8.25 \times 10^{-4}$ and 4.51 $\times 10^{-3}$, respectively). IRAK1-encoded interleukin 1 receptor-associated kinase 1 was also significantly involved in death receptor signalling, p75NTR receptor-mediated signalling, and p75NTR signals through NF- $\mathrm{BB}$, as identified by Reactome and IMPaLA. IRAK1 silencing in MCF7 cells was previously reported to decrease invasion, proliferation, and migration, with enhanced sensitivity to PTX [115]. Aggressive growth, PTX resistance, and metastasis were also reported in triple-negative breast cancer cells mediated via IRAK1 overexpression [116]. Recently, a large study including 1085 breast cancer patients showed a positive correlation of decreased IRAK1 expression and reduced tumour size following neoadjuvant chemotherapy [117]. A synergistic effect was also noticed through the downregulated phosphatidylinositol 3,4,5-triphosphate-dependent Rac exchanger 1 (PREX1, FC -1.06). Briefly, decreased MCF7 viability was reported for PREX1 loss by positive feedback to upstream phosphatidylinositol 3-kinase (P13K) activators [118]. In addition, a positive correlation was found between PREX1 overexpression and poor prognosis in breast cancer patients via neuregulin-ErbB signalling [119]. Similarly, the neuronal guanine nucleotide exchange factor (NGEF) overexpression was correlated with tumour progression and metastasis, including in breast carcinomas [120]; therefore, its decreased expression in the synergistic combination-treated cells will contribute to the overall synergistic effect of CBD with $\mathrm{SN}-38$ against MCF7 cells.

PCF11-encoded protein was among the top downregulated proteins in the combinationtreated MCF7 cells, with a fold change of -4.32 . PCF11 downregulation is associated with favourable outcomes in neuroblastoma patients [121], but its functional role in breast carcinoma is still unexplored. However, it was found to be involved in the alternative polyadenylation (APA), causing three prime untranslated region ( $3^{\prime}$ UTR) shortening of mRNA by cancer-specific ubiquitin ligase [17]. Additionally, aminoacylase 1 (ACY1) was also significantly downregulated (FC -4.16) in the CSN38-treated MCF7 cells compared to the monotherapies. ACY1 is responsible for amino acid deacylation during protein degradation and has been reported to be upregulated in colorectal cancer patients and HCT116 cells, promoting tumour progression [122,123]. ACY1 has been proposed as a tumour suppressor in small-cell lung cancer, renal cell carcinoma, and hepatocellular cancer cells, as its decreased expression in these cells may accumulate acylated peptide growth factors [124-126]. ACY1 was also downregulated in MCF7 cells treated with 17 $\beta$-estradiol, suggesting its role as a tumour suppressor in oestrogen-dependent breast carcinomas, but further studies are needed in order to evaluate its clinical relevance in breast cancer [127].

The downregulation of integrin subunit alpha L, nucleoporin 93, and signal peptide peptidase-like 2A encoded by the ITGAL, NUP93, and SPPL2A genes (FC - 2.01, -2.30, and -2.0 , respectively) contributed to the synergistic mechanisms of CBD and SN-38 against MCF7 cells. Briefly, ITGAL overexpression was reported in lymph node metastases of breast cancer patients, compared to the primary breast tumours, highlighting its role in breast cancer metastasis [128]. On the other hand, the overexpression of nucleoporin 93-a nuclear envelope protein-enhanced the migration and invasion of the triple-negative and claudin-low breast cancer cells alongside metastasis in animal models [129,130]. Moreover, the signal peptide peptidase was highly induced in breast and lung cancer cell lines, and its role in tumour progression is anticipated via FKBP8 degradation [131]. Collectively, in addition to its synergistic activity against MCF7-related breast adenocarcinomas, these findings indicate the potential therapeutic role of CSN-38 against other breast cancer subtypes, including triple-negative breast cancers. However, further studies involving a wide range of in vitro and in vivo breast cancer models are necessary in order to develop potential CBD-based adjuvants for breast cancer in the future. Moreover, CBD significantly synergized the SN-38- mediated inhibition of DNA topoisomerase 1 (TOP1) 
in MCF7 cells (FC $-1 ; p=0.01$ and $Q=0.03$ ), which contributed to the overall synergy between $\mathrm{CBD}$ and $\mathrm{SN}-38$ (Figure $8 \mathrm{~A}$ ).

\section{Material and Methods}

\subsection{Chemicals and Drug Preparation}

DOC, DOX, PTX, VIN, SN38, and CBD of $>98 \%$ purity were purchased from SigmaAldrich, NSW, Australia. A freshly prepared stock solution in dimethyl sulfoxide (DMSO) of 1 and $158.998 \mathrm{mM}$ was prepared for chemotherapeutic drugs and CBD, respectively. CBD was combined with drugs in nine different ratios (1:9, 2:8, 3:7, 4:6, 5:5, 6:4, 7:3, 8:2, and 9:1, $v / v$ ) for combination index (CI) analyses. Moreover, 50, 1, 2, 1, and $2 \mathrm{mM}$ stock in DMSO of DOC, DOX, PTX, VIN, and SN38, respectively, were prepared for synergy studies in a checkerboard design.

\subsection{Breast Adenocarcinoma Cell Line Culture Conditions}

MCF7 human breast adenocarcinoma cells were obtained from the American Type Culture Collection (ATCC: Manassas, VA, USA). Dulbecco's modified Eagle's medium (DMEM; Lonza, NSW, Australia) with $4.5 \mathrm{~g} / \mathrm{L}$ glucose, L-glutamine, and sodium pyruvate (Lonza Australia Pty Ltd., Mount Waverley, VIC, Australia), supplemented with 10\% foetal bovine serum (FBS; Interpath, Heidelberg West, VIC, Australia) and $100 \mathrm{U} / \mathrm{mL}$ of penicillin and streptomycin (Gibco ${ }^{\mathrm{TM}}$ BRL, Scoresby, VIC, Australia) was used to culture MCF7 cell line at $37^{\circ} \mathrm{C}$ in the presence of $5 \% \mathrm{CO}_{2}$.

\subsection{Cell Viability Determination}

Cellular viability was determined using the alamarBlue (resazurin) assay [132-134]. Briefly, in a 96-well plate, $100 \mu \mathrm{L}$ of the suspended MCF7 cells was seeded at $1 \times 10^{4} /$ well, and incubated at $37^{\circ} \mathrm{C}$ in the presence of $5 \% \mathrm{CO}_{2}$ overnight to adhere. The cells were treated with different concentrations of $\mathrm{CBD}$, chemotherapeutic drugs, and their combinations in different ratios, together with the vehicle control ( $0.5 \%$ dimethyl sulfoxide). After $72 \mathrm{~h}$, the medium was removed from the wells, and then $100 \mu \mathrm{L}$ of alamarBlue $(0.1 \mathrm{mg} / \mathrm{mL}$ in FBS free media) solution was added to each well and incubated for $4 \mathrm{~h}$ at $37^{\circ} \mathrm{C}$ in the presence of $5 \% \mathrm{CO}_{2}$. Using a microplate spectrophotometer (BMG CLARIO star, Victoria, Australia), the fluorescence was measured at an excitation wavelength of $555 \mathrm{~nm}$ and an emission wavelength of $595 \mathrm{~nm}$. Cell viability was determined as a percentage of vehicle-treated cells (control; 0.5\% DMSO).

\subsection{Synergy Quantification of CBD and Standard Chemotherapeutics against MCF7 Human Breast Adenocarcinoma Cells}

The potential interactions between CBD and the chemotherapeutic drugs were analysed using the combination index $(\mathrm{CI})$ model and the DrugComb portal [75]. CompuSyn version 2.0 (Biosoft, San Francisco, CA, USA) was used for the CI calculations based on the median-effect equation, which was derived from the mass-action law [135-137]. In the current study, nine pairwise combinations of chemotherapeutic drugs with CBD were studied in a constant ratio design, with a six-point dose-response curve in 1:2 serial dilution $(n=3)$, using the CI model (Chou-Talalay method) (Table 5) and 1:10 serially diluted chemotherapeutic drugs in the checkerboard design $(n=3)$ for better exploration of the interaction over a wider range of doses. The response data obtained from the CI model were further analysed in DrugComb, where the mean percentage of cell inhibition and the concentrations of the combined drugs were used as inputs for synergy scores in different models and combination sensitivity score (CSS) evaluation. 
Table 5. Molar ratios, concentrations, and codes of cannabidiol (CBD) combinations.

\begin{tabular}{cccc}
\hline \multirow{2}{*}{ Combination Code $^{*}$} & \multicolumn{2}{c}{ Highest Concentration $(\mu \mathrm{M})$} & $\begin{array}{c}\text { Molar Ratio } \\
\text { (CBD:Drug) }\end{array}$ \\
\cline { 2 - 3 } & CBD & Drug & $18: 1$ \\
\hline CXYZ19 & 15.9 & 0.9 & $40: 1$ \\
CXYZ28 & 31.8 & 0.8 & $68: 1$ \\
CXYZ37 & 47.7 & 0.7 & $106: 1$ \\
CXYZ46 & 63.6 & 0.6 & $159: 1$ \\
CXYZ55 & 79.5 & 0.5 & $238: 1$ \\
CXYZ64 & 95.4 & 0.4 & $371: 1$ \\
CXYZ73 & 111.3 & 0.3 & $636: 1$ \\
CXYZ82 & 127.2 & 0.2 & $1431: 1$ \\
CXYZ91 & 143.1 & 0.1 & \\
\hline
\end{tabular}

*: C refers to CBD; $\mathrm{XYZ}$ indicates initials of the chemotherapeutic drugs; the two-digit numbers refer to the combination with the corresponding molar ratio.

3.5. Flow Cytometric Analyses of Apoptosis in MCF7 Human Breast Adenocarcinoma Cells Using Annexin V-CF Blue and 7-Aminoactinomycin D (7AAD)

The apoptotic profiles of MCF7 cells were examined using Abcam Apoptosis Detection Kit (\#ab214663, Abcam, VIC, Australia) according to the manufacturer's protocol, after $24 \mathrm{~h}$ of treatment with CBD, chemotherapeutic drugs, and their most synergistic combination. Briefly, MCF7 cells were seeded at a density of $1 \times 10^{6}$ per mL in T75 cell culture flasks and treated with the vehicle control (0.5\% DMSO), selected synergistic CBD+ chemotherapeutic drug combinations, and monotherapies (individual treatment with CBD or chemotherapeutic drugs). The cell culture media were collected after $24 \mathrm{~h}$ of treatment, and cells were detached using $0.25 \% w / v$ of trypsin for 3 min at $37^{\circ} \mathrm{C}$. Trypsin was neutralised with an equal volume of $10 \%$ FBS-containing DMEM, and combined with the previously collected media. Cell pellets were collected by centrifugation at $500 \times g$ for $5 \mathrm{~min}$ at room temperature (RT), rinsed twice in PBS, resuspended in $1 \mathrm{~mL}$ PBS, and centrifuged again for $5 \mathrm{~min}$ at $500 \times \mathrm{g}$. The cell pellets harvested from all treatment and control groups were instantaneously resuspended in $0.5 \mathrm{~mL}$ of $1 \mathrm{X}$ binding buffer, and $5 \mu \mathrm{L}$ of annexin $\mathrm{V}-\mathrm{CF}$ blue and 7-AAD staining solutions were added to each $100 \mu \mathrm{L}$ of cell suspension. After 15 min of incubation in the dark, $400 \mu \mathrm{L}$ of $1 \mathrm{X}$ binding buffer was added. The cells were then examined using an ACEA Biosciences NovoCyte 3000 flow cytometer (ACEA Biosciences Inc., San Diego, CA, USA). For analysis and processing, the NovoExpress (version 1.5.0, ACEA Biosciences Inc., USA) software was implemented, where cells were gated on FSC vs. SSC to exclude the cell debris and aggregates. The cells were then gated on a dot plot of Annexin V-CF in Pacific Blue vs. 7-AAD fluorescence in PerCP, with a quadrant placed indicating live cells (+Annexin $\mathrm{V}$ and -7-AAD) in the lower-left quadrant, early apoptotic cells (+Annexin $\mathrm{V}$ and -7-AAD) in the lower-right quadrant, late apoptotic cells (+Annexin $\mathrm{V}$ and +7-AAD) in the upper-right quadrant, and necrotic cells (-Annexin $\mathrm{V}$ and +7-AAD) in the upper-left quadrant. Cell percentage data from each quadrant after each treatment $(n=3)$ were exported to GraphPad Prism for statistical analysis and visualisation. Annexin $\mathrm{V}$ and 7-AAD (7-aminoactinomycin $\mathrm{D}$ ) were combined to distinguish necrotic cells from early and late apoptotic cells. Annexin V binds to the phosphatidylserine (PS) phospholipids, which are translocated to the outer surface of cells during apoptosis [138]. 7-AAD, on the other hand, is a fluorescent dye that intercalates in double-stranded DNA, with a high affinity for guanine-cytosine residues, and is used as a fluorescent DNA marker in flow cytometry and fluorescence microscopy $[139,140]$. The PerCP and Pacific Blue channels were used for Annexin V and 7-AAD, respectively, as the emission spectra of these dyes do not overlap; therefore, no compensation is necessary [68]. 
3.6. Bottom-Up Label-Free Quantification Proteomics Study of MCF7 Cell Lysates after Treatment with the Most Synergistic Combination

\subsubsection{Cell Culture, Treatment, and Protein Extraction}

MCF7 cells were seeded at a density of $1.0 \times 10^{6}$ per mL cells in T75 flasks and incubated overnight at $37^{\circ} \mathrm{C}$ in the presence of $5 \% \mathrm{CO}_{2}$. The media were aspirated and replaced with fresh media containing $0.5 \%$ DMSO as the vehicle control, and the selected doses of chemotherapeutic drugs, $\mathrm{CBD}$, and their synergistic combinations, in triplicate, and incubated for $24 \mathrm{~h}$ at $37^{\circ} \mathrm{C}$ in the presence of $5 \% \mathrm{CO}_{2}$. Each cell flask was treated with $0.25 \% w / v$ trypsin for $3 \mathrm{~min}$ at $37^{\circ} \mathrm{C}$, and the cell culture media were collected. Trypsin was neutralised with an equal volume of $10 \%$ FBS-containing DMEM before mixing with the previously collected media. The cells were centrifuged at $500 \times g$ for $5 \mathrm{~min}$ at RT, and then the pellets were rinsed twice with ice-cold PBS and centrifuged again at $500 \times g$ for $5 \mathrm{~min}$. The cell pellets were then resuspended in $100 \mu \mathrm{L}$ of lysis buffer including $1 \mu \mathrm{L}$ of universal nuclease and fully mass spectrometry (MS)-compatible Halt ${ }^{\mathrm{TM}}$ Protease and Phosphatase Inhibitor Cocktail, EDTA-Free (Thermo Scientific, Waltham, MA, USA). The cells were pipetted up and down 10-15 times until the sample viscosity was reduced, and then placed on ice for $20 \mathrm{~min}$. The lysate was then centrifuged at $14,000 \mathrm{rpm}$ for $20 \mathrm{~min}$ at $4{ }^{\circ} \mathrm{C}$ and collected.

\subsubsection{Protein Quantification}

The Pierce ${ }^{\mathrm{TM}}$ Rapid Gold BCA Protein Assay Kit (\#A53226, Thermo Scientific, USA) was employed for the determination of protein concentration of the cell lysate, in triplicate, against bovine serum albumin (BSA) standard, as per the manufacturer's protocol. Briefly, 1 $\mu \mathrm{L}$ of each sample replicate was diluted 1:20 in water together with $20 \mu \mathrm{L}$ of each standard, and then placed in a 96-well plate with $200 \mu \mathrm{L}$ of working reagent per well. Samples were diluted until they were within the working range of $20-2,000 \mu \mathrm{g} \mathrm{mL}^{-1}$. The plate was mixed thoroughly on a plate shaker for $30 \mathrm{~s}$ and incubated at RT for $5 \mathrm{~min}$, and then the absorbance was measured within $20 \mathrm{~min}$ at $480 \mathrm{~nm}$ using a microplate spectrophotometer (BMG CLARIOstar, Melbourne, VIC, Australia). The blank absorbance was subtracted from all other readings of standards and samples, and sample concentration was determined against the established BSA standard calibration curve. Samples were stored at $-80{ }^{\circ} \mathrm{C}$ for further analysis.

\subsubsection{Preparation and Clean-Up of Peptides}

One-hundred-microgram protein samples were used for chemical and enzymatic sample processing using the EasyPep ${ }^{\mathrm{TM}}$ Mini MS Sample Prep Kit, as per the manufacturer's protocol (Thermo Fisher Scientific, USA). The final volume was adjusted to 100 $\mu \mathrm{L}$ using lysis buffer in a microcentrifuge tube. The reduction and alkylation solutions (50 $\mu \mathrm{L}$ each) were added, gently mixed, and incubated at $95^{\circ} \mathrm{C}$ using a heat block for $10 \mathrm{~min}$. The samples were allowed to cool at RT, and then $50 \mu \mathrm{L}$ of the reconstituted trypsin/lys-C protease mixture was added to each sample and incubated with shaking at $37^{\circ} \mathrm{C}$ for $3 \mathrm{~h}$. After incubation, $50 \mu \mathrm{L}$ of digestion stop solution was added and mixed gently. Peptide clean-up columns were implemented to remove hydrophilic and hydrophobic contaminants. Clean peptide samples were dried using a vacuum centrifuge and resuspended in $100 \mu \mathrm{L}$ of $0.1 \%$ formic acid in water for LC-MS analysis, and then carefully placed in maximum recovery sample vials (Waters Corp, Milford, MA, USA).

3.6.4. Label-Free Bottom-Up Quantification Proteomics Analysis via Nano-Ultra-High-Performance Liquid Chromatography Coupled with Quadruple Time-of-Flight Mass Spectrometry (Nano-UPLC-qTOF-MS)

A nanoACQUITY UPLC system (Waters Corp., Milford, MA, USA) coupled with a Synapt G2-S high-definition mass spectrometer (HDMS) (Waters Corp., Manchester, UK) operating in positive electron spray ion mode (ESI+) and equipped with a hybrid quadrupole time of flight (qTOF) analyser was used to analyse tryptic peptides. A Waters NanoLockSpray Exact Mass Ionization Source was utilised to maintain mass accuracy. 
Briefly, $100 \mathrm{fg}$ mL-1 Glu-fibrinopeptide B (GFP) dissolved in 50\% aqueous acetonitrile containing $0.1 \%$ formic acid with a lock mass $\mathrm{m} / \mathrm{z}$ of 785.84 .26 was infused as a lock spray solution at $0.5 \mu \mathrm{L} \mathrm{min}{ }^{-1}$ and calibrated against a sodium iodide solution. For the chromatographic separation of peptides, the nanoEase M/Z BEH C18 $(1.7 \mu \mathrm{m}, 130 \AA$, $75 \mu \mathrm{m} \times 100 \mathrm{~mm}$, Waters Corp., Milford, MA, USA) at $40{ }^{\circ} \mathrm{C}$ was utilised and coupled with a nanoEase M/Z Symmetry C18 Trap Column (100 $\AA, 5 \mu \mathrm{m}, 180 \mu \mathrm{m} \times 20 \mathrm{~mm}$, Waters Corp., Milford, MA, USA). Milli-Q water and acetonitrile containing $0.1 \%$ formic acid were used as mobile phases A and B, respectively (LCMS grade, Merck, Germany). An injection

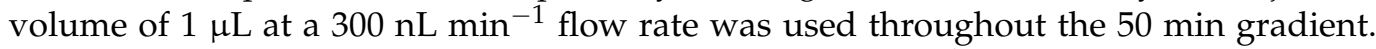

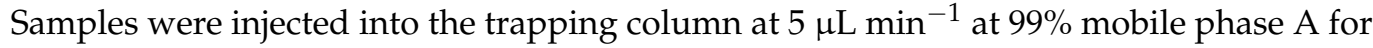
$3 \mathrm{~min}$, before being eluted to the analytical column. An initial 1\% of mobile phase B was ramped to $85 \%$ B over $50 \mathrm{~min}$ with the following gradient: $10 \% \mathrm{~B}$ at $2 \mathrm{~min}, 40 \% \mathrm{~B}$ at $40 \mathrm{~min}$, and $85 \% \mathrm{~B}$ at $42 \mathrm{~min}$. All samples were kept at $4{ }^{\circ} \mathrm{C}$ and were injected in duplicates. The ion source block temperature was set to $80^{\circ} \mathrm{C}$, and capillary voltage was maintained at $3 \mathrm{kV}$. Ions were acquired with $\mathrm{m} / \mathrm{z}$ between 50 and 2000, scanning time of $0.5 \mathrm{sec}$, sample cone voltage and source offset at $30 \mathrm{~V}$, nanoflow gas at $0.3 \mathrm{Bar}$, purge gas at $20 \mathrm{Lh}^{-1}$, and cone gas flow at $20 \mathrm{~L} \mathrm{~h}^{-1}$. A data-independent acquisition (DIA) method by MS${ }^{\mathrm{E}}$ multiplex mode was used for sample acquisition with a T-wave collision-induced dissociation cell filled with argon gas, using MassLynx Mass Spectrometry Software (Waters Corporation, Milford, MA, USA).

\subsubsection{Data Processing and Availability}

Progenesis QI software (Waters Corporation, Milford, MA, USA) was used to import and further process the MassLynx-acquired data. Automatic selection of alignment references among QC samples was set, and peptides were identified against the UniProt human proteome database (October 2020 version) using the ion accounting method, with a $250 \mathrm{kDa}$ protein mass maximum. One fragment per peptide or one peptide per protein together with 3 fragments per protein were set as ion matching requirements using relative quantification, implementing the Hi-N method $(n=3)$. Auto peptide and fragment tolerance, and less than $4 \%$ FDR, were set as search tolerance parameters. Peptides with absolute mass error $>20 \mathrm{ppm}$ or a single charge were further filtered out. Pairwise comparisons of the identified proteins in the treated groups were performed against the control group for cytotoxic potential exploration, while the most synergistic combination samples were compared against monotherapy-treated samples for the elucidation of possible synergistic mechanisms. In each experimental design, proteins with analysis of variance (ANOVA)-derived $p$-values of at least $\leq 0.05$ and q-values $\leq 0.05$, with a fold change $\geq 2$, were considered significant and included for further pathway analyses. Differentially expressed proteins identified by the quantitative processing of the LC-MS/MS analysis of the proteome tryptic digestion were analysed by STRING [80], Reactome [81], g:Profiler [82], and IMPaLA [83] to identify the relevant pathways responsible for the synergistic effect against MCF7 cells. The G: SCS algorithm was used for multiple testing corrections in the g:Profiler platform, with an adjusted $p$-value threshold of 0.05 . The raw and processed data have been deposited to the ProteomeXchange Consortium via the PRoteomics IDEntifications (PRIDE) repository [141], with the dataset identifiers PXD026587 and 10.6019/PXD026331.

\subsection{Statistical Analysis}

All statistical comparisons were performed using GraphPad Prism Version 9 (San Diego, CA, USA), except for the shotgun proteomics study, where MetaboAnalyst 5.0 was used together with Progenesis QIP (Waters Corporation, Milford, MA, USA). The significance was analysed via ANOVA and $t$-tests for multiple and pairwise comparisons, respectively. Data were expressed as means $\pm \mathrm{SD}$. Differences of at least $p<0.05$ between the mean values in the experiments were considered statistically significant. 


\section{Conclusions and Future Directions}

Synergistic interactions were observed between $\mathrm{CBD}$ and the five selected chemotherapeutic drugs at different molar ratios in MCF7 cells, using different synergy quantitation models. We highlighted the promising molar ratios of $\mathrm{CBD}$ and chemotherapeutic drug combinations that were validated against different synergy metrics. CBD synergistically enhanced the antiproliferative activity of the standard chemotherapeutic drugs by promoting apoptosis. Moreover, the presented pilot label-free quantification-driven proteomics study highlighted the cytotoxic mechanisms of CBD against MCF7 cells, along with the underlying synergistic mechanisms of its combination with $\mathrm{SN}-38$. However, further targeted proteomics studies with absolute quantification are warranted in order to validate the presented targets and pathways. Good tolerability and minimal adverse effects are reported for CBD in clinical trials (50-1000 $\mathrm{mg}$ /day up to 13 weeks), with an increased easing of legislation to approve CBD products. Nevertheless, further validation of the proposed combinations in normal, non-transformed breast epithelial cells is required.

The present study highlights potential new opportunities in breast cancer treatment with other chemotherapeutic agents, such as CDK or topoisomerase inhibitors. For example, we speculated the potential CBD combinations with CDK4/6 inhibitors such as abemaciclib, palbociclib, and ribociclib based on CBD-mediated inhibition of CDK-6 in MCF7 cells. The presented cytotoxic mechanisms of CBD are encouraging for further investigation of CBD's interaction with hormonal therapies, including aromatase inhibitors (such as anastrozole, letrozole, and exemestane), selective oestrogen receptor modulators (SERM such as tamoxifen or toremifene), and new generations of drugs such as fulvestrant and goserelin.

Collectively, CBD presents an opportunity to potentially enhance the effectiveness of the breast cancer treatment regimens containing doxorubicin, docetaxel, paclitaxel, $\mathrm{SN}-38$, and vinorelbine. Furthermore, the proposed combinations with CBD may be able to alleviate chemotherapy-induced adverse effects by reducing the dosage of chemotherapeutic drugs, or via CBD's ameliorative or protective activities. However, further in vivo and clinical studies are warranted in order to validate these in vitro findings.

Supplementary Materials: The following are available online at https:/ / www.mdpi.com/article/10 $.3390 /$ ijms221810103/s1.

Author Contributions: M.A.A.: conceptualization, methodology, investigation, data curation, writing original draft, review, and visualization; D.J.B.: conceptualization, funding, and review; M.N.L.: funding and review; D.C. and C.G.L.: conceptualization, funding, review, and supervision. All authors have read and agreed to the published version of the manuscript.

Funding: This research received no direct external funding, and the APC was partially funded by the NICM Health Research Institute, Western Sydney University, Australia.

Institutional Review Board Statement: Not applicable.

Informed Consent Statement: Not applicable.

Data Availability Statement: Shotgun proteomics data are available in the PRIDE repository with the dataset identifier PXD026587, and DOI:10.6019/PXD026587. All other data are presented within the article, or in Supplementary Files 1 and 2.

Acknowledgments: We acknowledge the partial support of Maxwell Family Foundation, Australia and Western Sydney University, Australia. Muhammad Alsherbiny would like to acknowledge the Missions sector, Ministry of Higher Education, Egypt, and the Research and Training Program, Western Sydney University, Australia, for supporting his PhD. The authors would like to thank Western Sydney University's Mass Spectrometry Facility for providing access to its instrumentation, and the assistance of Meena Mikhael (Facility Research Manager, Mass Spectrometry Unit, Western Sydney University) with the MS analyses. 
Conflicts of Interest: As a medical research institute, NICM Health Research Institute receives grants and donations from foundations, universities, government agencies, individuals, and industry. Sponsors and donors also provide untied funding to advance the vision and mission of the institute. The authors declare no conflict of interest.

$\begin{array}{ll}\text { Abbreviations } \\ \text { 4. EBP1 } & \text { Eukaryotic translation initiation factor 4E-binding protein 1 } \\ \text { 5-HT1A } & \text { Serotonin 1A receptor } \\ \text { AKT } & \text { Protein kinase B } \\ \text { CBD } & \text { Cannabidiol } \\ \text { CB1 and CB2 } & \text { Cannabinoid receptor 1 and 2 } \\ \text { CCL3 } & \text { Chemokine (C-C motif) ligand 3 } \\ \text { CDK } & \text { Cyclin-dependent kinase } \\ \text { CSS } & \text { Combination sensitivity score } \\ \text { DOC } & \text { Docetaxel } \\ \text { DOX } & \text { Doxorubicin } \\ \text { EGFR } & \text { Epidermal growth factor receptor } \\ \text { ER+/- } & \text { Oestrogen receptor-positive/negative } \\ \text { ETC } & \text { Electron transport chain } \\ \text { FC } & \text { Fold change } \\ \text { GM-CSF } & \text { Granulocyte-macrophage colony-stimulating factor } \\ \text { GPR55 } & \text { G protein-coupled receptor 55 } \\ \text { Id1 } & \text { DNA-binding protein inhibitor ID-1 } \\ \text { HER2+ } & \text { Human epidermal growth factor receptor 2 positive } \\ \text { HER3 } & \text { Human epidermal growth factor receptor 3 } \\ \text { HGNC } & \text { HUGO Gene Nomenclature Committee } \\ \text { MCM } & \text { Minichromosome maintenance proteins } \\ \text { MIP-2 } & \text { Macrophage Inflammatory Protein-2 } \\ \text { mTOR } & \text { Mechanistic target of rapamycin } \\ \text { NF- } \text { B } & \text { Nuclear factor kappa-light-chain-enhancer of activated B cells } \\ \text { ROS } & \text { Reactive oxygen species } \\ \text { PPAR- } \gamma & \text { Peroxisome proliferator-activated receptor gamma } \\ \text { PTX } & \text { Paclitaxel } \\ \text { SN-38 } & \text { 7-Ethyl-10-hydroxycamptothecin } \\ \text { TAM } & \text { Tumour-associated macrophage } \\ \text { TRPVs } & \text { Family of transient receptor potential (TRP) ion channel } \\ \text { TNBC } & \text { Triple-negative breast cancer } \\ \text { VIN } & \text { Vinorelbine } \\ & \end{array}$

\section{References}

1. Jett, J.; Stone, E.; Warren, G.; Cummings, K.M. Cannabis Use, Lung Cancer, and Related Issues. J. Thorac. Oncol. 2018, 13, 480-487. [CrossRef] [PubMed]

2. Pellati, F.; Borgonetti, V.; Brighenti, V.; Biagi, M.; Benvenuti, S.; Corsi, L. Cannabis sativa L. and Nonpsychoactive Cannabinoids: Their Chemistry and Role against Oxidative Stress, Inflammation, and Cancer. Biomed. Res. Int. 2018, 2018, 1691428. [CrossRef]

3. Good, P.; Haywood, A.; Gogna, G.; Martin, J.; Yates, P.; Greer, R.; Hardy, J. Oral medicinal cannabinoids to relieve symptom burden in the palliative care of patients with advanced cancer: A double-blind, placebo controlled, randomised clinical trial of efficacy and safety of cannabidiol (CBD). BMC Palliat. Care 2019, 18, 110. [CrossRef] [PubMed]

4. Turgeman, I.; Bar-Sela, G. Cannabis for cancer-illusion or the tip of an iceberg: A review of the evidence for the use of Cannabis and synthetic cannabinoids in oncology. Expert Opin. Investig. Drugs 2019, 28, 285-296. [CrossRef] [PubMed]

5. Chung, M.; Kim, H.K.; Abdi, S. Update on cannabis and cannabinoids for cancer pain. Curr. Opin. Anaesthesiol. 2020, 33, 825-831. [CrossRef]

6. Seltzer, E.S.; Watters, A.K.; MacKenzie, D.; Granat, L.M.; Zhang, D. Cannabidiol (CBD) as a Promising Anti-Cancer Drug. Cancers 2020, 12, 3203. [CrossRef]

7. Kis, B.; Ifrim, F.C.; Buda, V.; Avram, S.; Pavel, I.Z.; Antal, D.; Paunescu, V.; Dehelean, C.A.; Ardelean, F.; Diaconeasa, Z.; et al. Cannabidiol-from Plant to Human Body: A Promising Bioactive Molecule with Multi-Target Effects in Cancer. Int. J. Mol. Sci. 2019, 20, 5905. [CrossRef] [PubMed] 
8. Izzo, A.A.; Borrelli, F.; Capasso, R.; Di Marzo, V.; Mechoulam, R. Non-psychotropic plant cannabinoids: New therapeutic opportunities from an ancient herb. Trends Pharmacol. Sci. 2009, 30, 515-527. [CrossRef]

9. Kovalchuk, O.; Kovalchuk, I. Cannabinoids as anticancer therapeutic agents. Cell Cycle 2020, 19, 961-989. [CrossRef]

10. Schoeman, R.; Beukes, N.; Frost, C. Cannabinoid Combination Induces Cytoplasmic Vacuolation in MCF7 Breast Cancer Cells. Molecules 2020, 25, 4682. [CrossRef]

11. Franco, V.; Perucca, E. Pharmacological and Therapeutic Properties of Cannabidiol for Epilepsy. Drugs 2019, 79, 1435-1454. [CrossRef]

12. Samanta, D. Cannabidiol: A Review of Clinical Efficacy and Safety in Epilepsy. Pediatr. Neurol. 2019, 96, 24-29. [CrossRef] [PubMed]

13. Silvestro, S.; Mammana, S.; Cavalli, E.; Bramanti, P.; Mazzon, E. Use of Cannabidiol in the Treatment of Epilepsy: Efficacy and Security in Clinical Trials. Molecules 2019, 24, 1459. [CrossRef] [PubMed]

14. Arzimanoglou, A.; Brandl, U.; Cross, J.H.; Gil-Nagel, A.; Lagae, L.; Landmark, C.J.; Specchio, N.; Nabbout, R.; Thiele, E.A.; Gubbay, O.; et al. Epilepsy and cannabidiol: A guide to treatment. Epileptic Disord. 2020, 22, 1-14. [CrossRef] [PubMed]

15. Campos, A.C.; Fogaca, M.V.; Sonego, A.B.; Guimaraes, F.S. Cannabidiol, neuroprotection and neuropsychiatric disorders. Pharmacol. Res. 2016, 112, 119-127. [CrossRef]

16. Premoli, M.; Aria, F.; Bonini, S.A.; Maccarinelli, G.; Gianoncelli, A.; Pina, S.D.; Tambaro, S.; Memo, M.; Mastinu, A. Cannabidiol: Recent advances and new insights for neuropsychiatric disorders treatment. Life Sci. 2019, 224, 120-127. [CrossRef] [PubMed]

17. Li, H.; Liu, Y.; Tian, D.; Tian, L.; Ju, X.; Qi, L.; Wang, Y.; Liang, C. Overview of cannabidiol (CBD) and its analogues: Structures, biological activities, and neuroprotective mechanisms in epilepsy and Alzheimer's disease. Eur. J. Med. Chem 2020, 192, 112163. [CrossRef]

18. Pacher, P.; Kogan, N.M.; Mechoulam, R. Beyond THC and Endocannabinoids. Annu Rev. Pharmacol. Toxicol. 2020, 60, 637-659. [CrossRef]

19. FDA Approves First Drug Comprised of an Active Ingredient Derived from Marijuana to Treat Rare, Severe Forms of Epilepsy. Available online: https://www.fda.gov/news-events/press-announcements/fda-approves-first-drug-comprised-activeingredient-derived-marijuana-treat-rare-severe-forms (accessed on 12 August 2021).

20. Drug Enforcement Administration, D.o.J. Schedules of controlled substances: Placement in Schedule V of certain FDA-approved drugs containing cannabidiol; corresponding change to permit requirements. Final order. Fed. Regist. 2018, 83, 48950-48953.

21. Brunetti, P.; Faro, A.F.L.; Pirani, F.; Berretta, P.; Pacifici, R.; Pichini, S.; Busardò, F.P. Pharmacology and legal status of cannabidiol. Annali dell'Istituto Superiore di Sanità 2020, 56, 285-291.

22. Brunetti, P.; Pichini, S.; Pacifici, R.; Busardò, F.P.; del Rio, A. Herbal Preparations of Medical Cannabis: A Vademecum for Prescribing Doctors. Medicina 2020, 56, 237. [CrossRef]

23. Abd-Elsalam, W.H.; Alsherbiny, M.A.; Kung, J.Y.; Pate, D.W.; Lobenberg, R. LC-MS/MS quantitation of phytocannabinoids and their metabolites in biological matrices. Talanta 2019, 204, 846-867. [CrossRef]

24. Thomas, A.; Baillie, G.L.; Phillips, A.M.; Razdan, R.K.; Ross, R.A.; Pertwee, R.G. Cannabidiol displays unexpectedly high potency as an antagonist of CB1 and CB2 receptor agonists in vitro. Br. J. Pharmacol. 2007, 150, 613-623. [CrossRef]

25. Griffiths, C.; Aikins, J.; Warshal, D.; Ostrovsky, O. Can Cannabidiol Affect the Efficacy of Chemotherapy and Epigenetic Treatments in Cancer? Biomolecules 2021, 11, 766. [CrossRef] [PubMed]

26. Pertwee, R.G.; Ross, R.A.; Craib, S.J.; Thomas, A. (-)-Cannabidiol antagonizes cannabinoid receptor agonists and noradrenaline in the mouse vas deferens. Eur. J. Pharmacol. 2002, 456, 99-106. [CrossRef]

27. Ibeas Bih, C.; Chen, T.; Nunn, A.V.; Bazelot, M.; Dallas, M.; Whalley, B.J. Molecular Targets of Cannabidiol in Neurological Disorders. Neurotherapeutics 2015, 12, 699-730. [CrossRef] [PubMed]

28. De la Harpe, A.; Beukes, N.; Frost, C.L. CBD activation of TRPV1 induces oxidative signaling and subsequent ER stress in breast cancer cell lines. Biotechnol. Appl. Biochem. 2021, 1-11. [CrossRef]

29. Jeong, S.; Jo, M.J.; Yun, H.K.; Kim, D.Y.; Kim, B.R.; Kim, J.L.; Park, S.H.; Na, Y.J.; Jeong, Y.A.; Kim, B.G.; et al. Cannabidiol promotes apoptosis via regulation of XIAP/Smac in gastric cancer. Cell Death Dis. 2019, 10, 846. [CrossRef]

30. Mould, R.R.; Botchway, S.W.; Parkinson, J.R.C.; Thomas, E.L.; Guy, G.W.; Bell, J.D.; Nunn, A.V.W. Cannabidiol Modulates Mitochondrial Redox and Dynamics in MCF7 Cancer Cells: A Study Using Fluorescence Lifetime Imaging Microscopy of NAD(P)H. Front. Mol. Biosci. 2021, 8, 630107. [CrossRef] [PubMed]

31. Trac, J.; Keck, J.M.; Deweese, J.E. Cannabidiol oxidation product HU-331 is a potential anticancer cannabinoid-quinone: A narrative review. J. Cannabis Res. 2021, 3, 11. [CrossRef] [PubMed]

32. Ferlay, J.; Soerjomataram, I.; Dikshit, R.; Eser, S.; Mathers, C.; Rebelo, M.; Parkin, D.M.; Forman, D.; Bray, F. Cancer incidence and mortality worldwide: Sources, methods and major patterns in GLOBOCAN 2012. Int. J. Cancer 2015, 136, E359-E386. [CrossRef]

33. Bray, F.; Ferlay, J.; Soerjomataram, I.; Siegel, R.L.; Torre, L.A.; Jemal, A. Global cancer statistics 2018: GLOBOCAN estimates of incidence and mortality worldwide for 36 cancers in 185 countries. CA Cancer J. Clin. 2018, 68, 394-424. [CrossRef] [PubMed]

34. Ligresti, A.; Moriello, A.S.; Starowicz, K.; Matias, I.; Pisanti, S.; De Petrocellis, L.; Laezza, C.; Portella, G.; Bifulco, M.; Di Marzo, V. Antitumor activity of plant cannabinoids with emphasis on the effect of cannabidiol on human breast carcinoma. J. Pharmacol. Exp. Ther. 2006, 318, 1375-1387. [CrossRef] [PubMed]

35. Sultan, A.S.; Marie, M.A.; Sheweita, S.A. Novel mechanism of cannabidiol-induced apoptosis in breast cancer cell lines. Breast 2018, 41, 34-41. [CrossRef] 
36. Elbaz, M.; Nasser, M.W.; Ravi, J.; Wani, N.A.; Ahirwar, D.K.; Zhao, H.; Oghumu, S.; Satoskar, A.R.; Shilo, K.; Carson, W.E.; et al. Modulation of the tumor microenvironment and inhibition of EGF/EGFR pathway: Novel anti-tumor mechanisms of Cannabidiol in breast cancer. Mol. Oncol. 2015, 9, 906-919. [CrossRef]

37. McAllister, S.D.; Christian, R.T.; Horowitz, M.P.; Garcia, A.; Desprez, P.Y. Cannabidiol as a novel inhibitor of Id-1 gene expression in aggressive breast cancer cells. Mol. Cancer Ther. 2007, 6, 2921-2927. [CrossRef]

38. Fraguas-Sanchez, A.I.; Fernandez-Carballido, A.; Simancas-Herbada, R.; Martin-Sabroso, C.; Torres-Suarez, A.I. CBD loaded microparticles as a potential formulation to improve paclitaxel and doxorubicin-based chemotherapy in breast cancer. Int. J. Pharm. 2020, 574, 118916. [CrossRef]

39. Shrivastava, A.; Kuzontkoski, P.M.; Groopman, J.E.; Prasad, A. Cannabidiol induces programmed cell death in breast cancer cells by coordinating the cross-talk between apoptosis and autophagy. Mol. Cancer Ther. 2011, 10, 1161-1172. [CrossRef]

40. Gewirtz, D.A. The Endocannabinoid System as a Target. for Treatment of Breast Cancer; Virginia Commonwealth University: Richmond, VA, USA, 2010.

41. Bergamaschi, M.M.; Queiroz, R.H.; Chagas, M.H.; de Oliveira, D.C.; De Martinis, B.S.; Kapczinski, F.; Quevedo, J.; Roesler, R.; Schröder, N.; Nardi, A.E.; et al. Cannabidiol reduces the anxiety induced by simulated public speaking in treatment-naïve social phobia patients. Neuropsychopharmacology 2011, 36, 1219-1226. [CrossRef]

42. Crippa, J.A.; Derenusson, G.N.; Ferrari, T.B.; Wichert-Ana, L.; Duran, F.L.; Martin-Santos, R.; Simões, M.V.; Bhattacharyya, S.; Fusar-Poli, P.; Atakan, Z.; et al. Neural basis of anxiolytic effects of cannabidiol (CBD) in generalized social anxiety disorder: A preliminary report. J. Psychopharmacol. 2011, 25, 121-130. [CrossRef]

43. Crippa, J.A.; Zuardi, A.W.; Garrido, G.E.; Wichert-Ana, L.; Guarnieri, R.; Ferrari, L.; Azevedo-Marques, P.M.; Hallak, J.E.; McGuire, P.K.; Filho Busatto, G. Effects of cannabidiol (CBD) on regional cerebral blood flow. Neuropsychopharmacology 2004, 29, 417-426. [CrossRef]

44. Zuardi, A.W.; Rodrigues, N.P.; Silva, A.L.; Bernardo, S.A.; Hallak, J.E.C.; Guimarães, F.S.; Crippa, J.A.S. Inverted U-Shaped Dose-Response Curve of the Anxiolytic Effect of Cannabidiol during Public Speaking in Real Life. Front. Pharmacol. 2017, 8, 259. [CrossRef]

45. Martin-Santos, R.; Crippa, J.A.; Batalla, A.; Bhattacharyya, S.; Atakan, Z.; Borgwardt, S.; Allen, P.; Seal, M.; Langohr, K.; Farré, M.; et al. Acute effects of a single, oral dose of d9-tetrahydrocannabinol (THC) and cannabidiol (CBD) administration in healthy volunteers. Curr Pharm Des. 2012, 18, 4966-4979. [CrossRef] [PubMed]

46. Bhattacharyya, S.; Morrison, P.D.; Fusar-Poli, P.; Martin-Santos, R.; Borgwardt, S.; Winton-Brown, T.; Nosarti, C.; CM, O.C.; Seal, M.; Allen, P.; et al. Opposite effects of delta-9-tetrahydrocannabinol and cannabidiol on human brain function and psychopathology. Neuropsychopharmacology 2010, 35, 764-774. [CrossRef]

47. Hallak, J.E.; Machado-de-Sousa, J.P.; Crippa, J.A.; Sanches, R.F.; Trzesniak, C.; Chaves, C.; Bernardo, S.A.; Regalo, S.C.; Zuardi, A.W. Performance of schizophrenic patients in the Stroop Color Word Test and electrodermal responsiveness after acute administration of cannabidiol (CBD). Br. J. Psychiatry 2010, 32, 56-61. [CrossRef] [PubMed]

48. Linares, I.M.; Zuardi, A.W.; Pereira, L.C.; Queiroz, R.H.; Mechoulam, R.; Guimarães, F.S.; Crippa, J.A. Cannabidiol presents an inverted U-shaped dose-response curve in a simulated public speaking test. Br. J. Psychiatry 2019, 41, 9-14. [CrossRef] [PubMed]

49. Hundal, H.; Lister, R.; Evans, N.; Antley, A.; Englund, A.; Murray, R.M.; Freeman, D.; Morrison, P.D. The effects of cannabidiol on persecutory ideation and anxiety in a high trait paranoid group. J. Psychopharmacol. 2018, 32, 276-282. [CrossRef] [PubMed]

50. Boggs, D.L.; Surti, T.; Gupta, A.; Gupta, S.; Niciu, M.; Pittman, B.; Schnakenberg Martin, A.M.; Thurnauer, H.; Davies, A.; D'Souza, D.C.; et al. The effects of cannabidiol (CBD) on cognition and symptoms in outpatients with chronic schizophrenia a randomized placebo controlled trial. Psychopharmacology 2018, 235, 1923-1932. [CrossRef]

51. McGuire, P.; Robson, P.; Cubala, W.J.; Vasile, D.; Morrison, P.D.; Barron, R.; Taylor, A.; Wright, S. Cannabidiol (CBD) as an Adjunctive Therapy in Schizophrenia: A Multicenter Randomized Controlled Trial. Am. J. Psychiatry 2018, 175, $225-231$. [CrossRef]

52. Irving, P.M.; Iqbal, T.; Nwokolo, C.; Subramanian, S.; Bloom, S.; Prasad, N.; Hart, A.; Murray, C.; Lindsay, J.O.; Taylor, A.; et al. A Randomized, Double-blind, Placebo-controlled, Parallel-group, Pilot Study of Cannabidiol-rich Botanical Extract in the Symptomatic Treatment of Ulcerative Colitis. Inflamm. Bowel Dis. 2018, 24, 714-724. [CrossRef]

53. Jadoon, K.A.; Ratcliffe, S.H.; Barrett, D.A.; Thomas, E.L.; Stott, C.; Bell, J.D.; O'Sullivan, S.E.; Tan, G.D. Efficacy and Safety of Cannabidiol and Tetrahydrocannabivarin on Glycemic and Lipid Parameters in Patients With Type 2 Diabetes: A Randomized, Double-Blind, Placebo-Controlled, Parallel Group Pilot Study. Diabetes Care 2016, 39, 1777-1786. [CrossRef] [PubMed]

54. Larsen, C.; Shahinas, J. Dosage, Efficacy and Safety of Cannabidiol Administration in Adults: A Systematic Review of Human Trials. J. Clin. Med. Res. 2020, 12, 129-141. [CrossRef] [PubMed]

55. McAllister, S.D.; Murase, R.; Christian, R.T.; Lau, D.; Zielinski, A.J.; Allison, J.; Almanza, C.; Pakdel, A.; Lee, J.; Limbad, C.; et al. Pathways mediating the effects of cannabidiol on the reduction of breast cancer cell proliferation, invasion, and metastasis. Breast Cancer Res. Treat. 2011, 129, 37-47. [CrossRef] [PubMed]

56. Murase, R.; Kawamura, R.; Singer, E.; Pakdel, A.; Sarma, P.; Judkins, J.; Elwakeel, E.; Dayal, S.; Martinez-Martinez, E.; Amere, M.; et al. Targeting multiple cannabinoid anti-tumour pathways with a resorcinol derivative leads to inhibition of advanced stages of breast cancer. Br. J. Pharmacol. 2014, 171, 4464-4477. [CrossRef] [PubMed]

57. Kosgodage, U.S.; Mould, R.; Henley, A.B.; Nunn, A.V.; Guy, G.W.; Thomas, E.L.; Inal, J.M.; Bell, J.D.; Lange, S. Cannabidiol (CBD) Is a Novel Inhibitor for Exosome and Microvesicle (EMV) Release in Cancer. Front. Pharmacol. 2018, 9, 889. [CrossRef] 
58. Keith, C.T.; Borisy, A.A.; Stockwell, B.R. Multicomponent therapeutics for networked systems. Nat. Rev. Drug Discov. 2005, 4, 71-78. [CrossRef]

59. Zimmermann, G.R.; Lehar, J.; Keith, C.T. Multi-target therapeutics: When the whole is greater than the sum of the parts. Drug Discov. Today 2007, 12, 34-42. [CrossRef]

60. Yeh, P.J.; Hegreness, M.J.; Aiden, A.P.; Kishony, R. Drug interactions and the evolution of antibiotic resistance. Nat. Rev. Microbiol. 2009, 7, 460-466. [CrossRef]

61. Bhuyan, D.J.; Perera, S.; Kaur, K.; Alsherbiny, M.A.; Low, M.; Seto, S.-W.; Li, C.-G.; Zhou, X. Synergistic Effects of Chinese Herbal Medicine and Biological Networks. Approaching Complex. Dis. 2020, 393-436.

62. Ward, S.J.; McAllister, S.D.; Kawamura, R.; Murase, R.; Neelakantan, H.; Walker, E.A. Cannabidiol inhibits paclitaxel-induced neuropathic pain through 5-HT(1A) receptors without diminishing nervous system function or chemotherapy efficacy. Br. J. Pharmacol. 2014, 171, 636-645. [CrossRef]

63. Hao, E.; Mukhopadhyay, P.; Cao, Z.; Erdelyi, K.; Holovac, E.; Liaudet, L.; Lee, W.S.; Hasko, G.; Mechoulam, R.; Pacher, P. Cannabidiol Protects against Doxorubicin-Induced Cardiomyopathy by Modulating Mitochondrial Function and Biogenesis. Mol. Med. 2015, 21, 38-45. [CrossRef] [PubMed]

64. Alsherbiny, M.A.; Li, C.G. Medicinal Cannabis-Potential Drug Interactions. Medicines 2019, 6, 3. [CrossRef]

65. Huestis, M.A.; Solimini, R.; Pichini, S.; Pacifici, R.; Carlier, J.; Busardò, F.P. Cannabidiol adverse effects and toxicity. Curr. Neuropharmacol. 2019, 17, 974-989. [CrossRef]

66. Meyer, C.T.; Wooten, D.J.; Lopez, C.F.; Quaranta, V. Charting the Fragmented Landscape of Drug Synergy. Trends Pharmacol. Sci. 2020, 41, 266-280. [CrossRef]

67. Vlot, A.H.; Aniceto, N.; Menden, M.P.; Ulrich-Merzenich, G.; Bender, A. Applying drug synergy metrics to oncology combination screening data: Agreements, disagreements and pitfalls. Drug Discov. Today 2019, 24, 2286-2298. [CrossRef]

68. Alsherbiny, M.A.; Bhuyan, D.J.; Radwan, I.; Chang, D.; Li, C.G. Metabolomic Identification of Anticancer Metabolites of Australian Propolis and Proteomic Elucidation of Its Synergistic Mechanisms with Doxorubicin in the MCF7 Cells. Int. J. Mol. Sci. 2021, 22, 7840. [CrossRef]

69. Gilvary, C.; Dry, J.R.; Elemento, O. Multi-task learning predicts drug combination synergy in cells and in the clinic. bioRxiv 2019, 576017. [CrossRef]

70. Lee, A.V.; Oesterreich, S.; Davidson, N.E. MCF7 Cells—Changing the Course of Breast Cancer Research and Care for 45 Years. JNCI J. Natl. Cancer Inst. 2015, 107. [CrossRef]

71. NCI. Stages of Breast Cancer. Available online: https://www.cancer.gov/types/breast/patient/breast-treatment-pdq\#link/_148 (accessed on 11 September 2018).

72. Chou, T.-C. The combination index $(\mathrm{CI}<1)$ as the definition of synergism and of synergy claims. Synergy 2018, 7, 49-50.

73. O'Neil, J.; Benita, Y.; Feldman, I.; Chenard, M.; Roberts, B.; Liu, Y.; Li, J.; Kral, A.; Lejnine, S.; Loboda, A.; et al. An Unbiased Oncology Compound Screen to Identify Novel Combination Strategies. Mol. Cancer Ther. 2016, 15, 1155-1162. [CrossRef] [PubMed]

74. Doroshow, J.H.; Simon, R.M. On the Design of Combination Cancer Therapy. Cell 2017, 171, 1476-1478. [CrossRef]

75. Zagidullin, B.; Aldahdooh, J.; Zheng, S.; Wang, W.; Wang, Y.; Saad, J.; Malyutina, A.; Jafari, M.; Tanoli, Z.; Pessia, A.; et al. DrugComb: An integrative cancer drug combination data portal. Nucleic Acids Res. 2019, 47, W43-W51. [CrossRef] [PubMed]

76. Fouad, A.A.; Albuali, W.H.; Al-Mulhim, A.S.; Jresat, I. Cardioprotective effect of cannabidiol in rats exposed to doxorubicin toxicity. Environ. Toxicol. Pharmacol. 2013, 36, 347-357. [CrossRef]

77. King, K.M.; Myers, A.M.; Soroka-Monzo, A.J.; Tuma, R.F.; Tallarida, R.J.; Walker, E.A.; Ward, S.J. Single and combined effects of Delta(9) -tetrahydrocannabinol and cannabidiol in a mouse model of chemotherapy-induced neuropathic pain. Br. J. Pharmacol. 2017, 174, 2832-2841. [CrossRef] [PubMed]

78. De Petrocellis, L.; Ligresti, A.; Schiano Moriello, A.; Iappelli, M.; Verde, R.; Stott, C.G.; Cristino, L.; Orlando, P.; Di Marzo, V. Non-THC cannabinoids inhibit prostate carcinoma growth in vitro and in vivo: Pro-apoptotic effects and underlying mechanisms. Br. J. Pharmacol. 2013, 168, 79-102. [CrossRef]

79. Engels, F.K.; de Jong, F.A.; Sparreboom, A.; Mathot, R.A.; Loos, W.J.; Kitzen, J.J.; de Bruijn, P.; Verweij, J.; Mathijssen, R.H. Medicinal cannabis does not influence the clinical pharmacokinetics of irinotecan and docetaxel. Oncologist 2007, 12, 291-300. [CrossRef] [PubMed]

80. Szklarczyk, D.; Morris, J.H.; Cook, H.; Kuhn, M.; Wyder, S.; Simonovic, M.; Santos, A.; Doncheva, N.T.; Roth, A.; Bork, P. The STRING database in 2017: Quality-controlled protein-protein association networks, made broadly accessible. Nucleic Acids Res. 2016, 45, gkw937. [CrossRef] [PubMed]

81. Fabregat, A.; Jupe, S.; Matthews, L.; Sidiropoulos, K.; Gillespie, M.; Garapati, P.; Haw, R.; Jassal, B.; Korninger, F.; May, B.; et al. The Reactome Pathway Knowledgebase. Nucleic Acids Res. 2018, 46, D649-D655. [CrossRef]

82. Reimand, J.; Isserlin, R.; Voisin, V.; Kucera, M.; Tannus-Lopes, C.; Rostamianfar, A.; Wadi, L.; Meyer, M.; Wong, J.; Xu, C.; et al. Pathway enrichment analysis and visualization of omics data using g:Profiler, GSEA, Cytoscape and EnrichmentMap. Nat. Protoc. 2019, 14, 482-517. [CrossRef]

83. Kamburov, A.; Cavill, R.; Ebbels, T.M.; Herwig, R.; Keun, H.C. Integrated pathway-level analysis of transcriptomics and metabolomics data with IMPaLA. Bioinformatics 2011, 27, 2917-2918. [CrossRef] [PubMed] 
84. Bertram, R.; Gram Pedersen, M.; Luciani, D.S.; Sherman, A. A simplified model for mitochondrial ATP production. J. Theor. Biol. 2006, 243, 575-586. [CrossRef]

85. Bonora, M.; Patergnani, S.; Rimessi, A.; De Marchi, E.; Suski, J.M.; Bononi, A.; Giorgi, C.; Marchi, S.; Missiroli, S.; Poletti, F.; et al. ATP synthesis and storage. Purinergic Signal. 2012, 8, 343-357. [CrossRef]

86. Urra, F.A.; Munoz, F.; Lovy, A.; Cardenas, C. The Mitochondrial Complex(I)ty of Cancer. Front. Oncol. 2017, 7, 118. [CrossRef]

87. Chan, J.Z.; Duncan, R.E. Regulatory Effects of Cannabidiol on Mitochondrial Functions: A Review. Cells 2021, 10, 1251. [CrossRef] [PubMed]

88. Jeong, S.; Yun, H.K.; Jeong, Y.A.; Jo, M.J.; Kang, S.H.; Kim, J.L.; Kim, D.Y.; Park, S.H.; Kim, B.R.; Na, Y.J.; et al. Cannabidiol-induced apoptosis is mediated by activation of Noxa in human colorectal cancer cells. Cancer Lett. 2019, 447, 12-23. [CrossRef]

89. Perez-Sayans, M.; Somoza-Martin, J.M.; Barros-Angueira, F.; Rey, J.M.; Garcia-Garcia, A. V-ATPase inhibitors and implication in cancer treatment. Cancer Treat. Rev. 2009, 35, 707-713. [CrossRef]

90. Hu, B.; Guo, Y. Inhibition of mitochondrial translation as a therapeutic strategy for human ovarian cancer to overcome chemoresistance. Biochem. Biophys. Res. Commun. 2019, 509, 373-378. [CrossRef] [PubMed]

91. Skrtic, M.; Sriskanthadevan, S.; Jhas, B.; Gebbia, M.; Wang, X.; Wang, Z.; Hurren, R.; Jitkova, Y.; Gronda, M.; Maclean, N.; et al. Inhibition of mitochondrial translation as a therapeutic strategy for human acute myeloid leukemia. Cancer Cell 2011, 20, 674-688. [CrossRef] [PubMed]

92. Nebenfuehr, S.; Kollmann, K.; Sexl, V. The role of CDK6 in cancer. Int. J. Cancer 2020, 147, 2988-2995. [CrossRef]

93. Yang, C.; Li, Z.; Bhatt, T.; Dickler, M.; Giri, D.; Scaltriti, M.; Baselga, J.; Rosen, N.; Chandarlapaty, S. Acquired CDK6 amplification promotes breast cancer resistance to CDK4/6 inhibitors and loss of ER signaling and dependence. Oncogene 2017, 36, 2255-2264. [CrossRef]

94. Bai, J.; Yong, H.M.; Chen, F.F.; Mei, P.J.; Liu, H.; Li, C.; Pan, Z.Q.; Wu, Y.P.; Zheng, J.N. Cullin1 is a novel marker of poor prognosis and a potential therapeutic target in human breast cancer. Ann. Oncol. 2013, 24, 2016-2022. [CrossRef]

95. Ren, Z.Q.; Yan, W.J.; Zhang, X.Z.; Zhang, P.B.; Zhang, C.; Chen, S.K. CUL1 Knockdown Attenuates the Adhesion, Invasion, and Migration of Triple-Negative Breast Cancer Cells via Inhibition of Epithelial-Mesenchymal Transition. Pathol. Oncol. Res. 2020, 26, 1153-1163. [CrossRef]

96. Huang, Y.F.; Zhang, Z.; Zhang, M.; Chen, Y.S.; Song, J.; Hou, P.F.; Yong, H.M.; Zheng, J.N.; Bai, J. CUL1 promotes breast cancer metastasis through regulating EZH2-induced the autocrine expression of the cytokines CXCL8 and IL11. Cell Death Dis. 2018, 10, 2. [CrossRef]

97. Gou, K.; Liu, J.; Feng, X.; Li, H.; Yuan, Y.; Xing, C. Expression of Minichromosome Maintenance Proteins (MCM) and Cancer Prognosis: A meta-analysis. J. Cancer 2018, 9, 1518-1526. [CrossRef]

98. Qin, T.; Huang, G.; Chi, L.; Sui, S.; Song, C.; Li, N.; Sun, S.; Li, N.; Zhang, M.; Zhao, Z.; et al. Exceptionally high UBE2C expression is a unique phenomenon in basal-like type breast cancer and is regulated by BRCA1. Biomed. Pharmacother. 2017, 95, 649-655. [CrossRef] [PubMed]

99. Rawat, A.; Gopal, G.; Selvaluxmy, G.; Rajkumar, T. Inhibition of ubiquitin conjugating enzyme UBE2C reduces proliferation and sensitizes breast cancer cells to radiation, doxorubicin, tamoxifen and letrozole. Cell Oncol. 2013, 36, 459-467. [CrossRef]

100. Hande, K.R. Topoisomerase II inhibitors. Update Cancer Ther. 2008, 3, 13-26. [CrossRef]

101. Xu, W.X.; Song, W.; Jiang, M.P.; Yang, S.J.; Zhang, J.; Wang, D.D.; Tang, J.H. Systematic Characterization of Expression Profiles and Prognostic Values of the Eight Subunits of the Chaperonin TRiC in Breast Cancer. Front. Genet. 2021, 12, 637887. [CrossRef]

102. Banin, S.; Moyal, L.; Shieh, S.; Taya, Y.; Anderson, C.W.; Chessa, L.; Smorodinsky, N.I.; Prives, C.; Reiss, Y.; Shiloh, Y.; et al. Enhanced phosphorylation of p53 by ATM in response to DNA damage. Science 1998, 281, 1674-1677. [CrossRef] [PubMed]

103. Canman, C.E.; Lim, D.S.; Cimprich, K.A.; Taya, Y.; Tamai, K.; Sakaguchi, K.; Appella, E.; Kastan, M.B.; Siliciano, J.D. Activation of the ATM kinase by ionizing radiation and phosphorylation of p53. Science 1998, 281, 1677-1679. [CrossRef] [PubMed]

104. Shiloh, Y.; Kastan, M.B. ATM: Genome stability, neuronal development, and cancer cross paths. Adv. Cancer Res. 2001, 83, 209-254. [CrossRef] [PubMed]

105. Savitsky, K.; Bar-Shira, A.; Gilad, S.; Rotman, G.; Ziv, Y.; Vanagaite, L.; Tagle, D.A.; Smith, S.; Uziel, T.; Sfez, S.; et al. A single ataxia telangiectasia gene with a product similar to PI-3 kinase. Science 1995, 268, 1749-1753. [CrossRef]

106. Tanic, M.; Krivokuca, A.; Cavic, M.; Mladenovic, J.; Plesinac Karapandzic, V.; Beck, S.; Radulovic, S.; Susnjar, S.; Jankovic, R. Molecular signature of response to preoperative radiotherapy in locally advanced breast cancer. Radiat. Oncol. 2018, $13,193$. [CrossRef]

107. Vazquez, A.; Liu, J.; Zhou, Y.; Oltvai, Z.N. Catabolic efficiency of aerobic glycolysis: The Warburg effect revisited. BMC Syst. Biol. 2010, 4, 58. [CrossRef]

108. Alfarouk, K.O.; Verduzco, D.; Rauch, C.; Muddathir, A.K.; Adil, H.H.; Elhassan, G.O.; Ibrahim, M.E.; David Polo Orozco, J.; Cardone, R.A.; Reshkin, S.J.; et al. Glycolysis, tumor metabolism, cancer growth and dissemination. A new $\mathrm{pH}$-based etiopathogenic perspective and therapeutic approach to an old cancer question. Oncoscience 2014, 1, 777-802. [CrossRef]

109. Garcia-Flores, A.E.; Sollome, J.J.; Thavathiru, E.; Bower, J.L.; Vaillancourt, R.R. HER2/HER3 regulates lactate secretion and expression of lactate receptor mRNA through the MAP3K4 associated protein GIT1. Sci. Rep. 2019, 9, 10823. [CrossRef]

110. Chia, J.; Tham, K.M.; Gill, D.J.; Bard-Chapeau, E.A.; Bard, F.A. ERK8 is a negative regulator of O-GalNAc glycosylation and cell migration. eLife 2014, 3, e01828. [CrossRef] 
111. Gill, D.J.; Tham, K.M.; Chia, J.; Wang, S.C.; Steentoft, C.; Clausen, H.; Bard-Chapeau, E.A.; Bard, F.A. Initiation of GalNAc-type Oglycosylation in the endoplasmic reticulum promotes cancer cell invasiveness. Proc. Natl. Acad. Sci. USA 2013, 110, E3152-E3161. [CrossRef] [PubMed]

112. Perez-Salvia, M.; Simo-Riudalbas, L.; Llinas-Arias, P.; Roa, L.; Setien, F.; Soler, M.; de Moura, M.C.; Bradner, J.E.; Gonzalez-Suarez, E.; Moutinho, C.; et al. Bromodomain inhibition shows antitumoral activity in mice and human luminal breast cancer. Oncotarget 2017, 8, 51621-51629. [CrossRef]

113. Zoppino, F.C.M.; Guerrero-Gimenez, M.E.; Castro, G.N.; Ciocca, D.R. Comprehensive transcriptomic analysis of heat shock proteins in the molecular subtypes of human breast cancer. BMC Cancer 2018, 18, 700. [CrossRef] [PubMed]

114. Buttacavoli, M.; Di Cara, G.; D'Amico, C.; Geraci, F.; Pucci-Minafra, I.; Feo, S.; Cancemi, P. Prognostic and Functional Significant of Heat Shock Proteins (HSPs) in Breast Cancer Unveiled by Multi-Omics Approaches. Biology 2021, 10, 247. [CrossRef] [PubMed]

115. Li, Y.; Li, W.; Lin, J.; Lv, C.; Qiao, G. miR-146a Enhances the Sensitivity of Breast Cancer Cells to Paclitaxel by Downregulating IRAK1. Cancer Biother. Radiopharm. 2020. [CrossRef]

116. Wee, Z.N.; Yatim, S.M.; Kohlbauer, V.K.; Feng, M.; Goh, J.Y.; Bao, Y.; Lee, P.L.; Zhang, S.; Wang, P.P.; Lim, E.; et al. IRAK1 is a therapeutic target that drives breast cancer metastasis and resistance to paclitaxel. Nat. Commun. 2015, 6, 8746. [CrossRef]

117. Yang, M.; Qin, X.; Qin, G.; Zheng, X. The role of IRAK1 in breast cancer patients treated with neoadjuvant chemotherapy. Onco. Targets Ther. 2019, 12, 2171-2180. [CrossRef]

118. Dillon, L.M.; Bean, J.R.; Yang, W.; Shee, K.; Symonds, L.K.; Balko, J.M.; McDonald, W.H.; Liu, S.; Gonzalez-Angulo, A.M.; Mills, G.B.; et al. P-REX1 creates a positive feedback loop to activate growth factor receptor, PI3K/AKT and MEK/ERK signaling in breast cancer. Oncogene 2015, 34, 3968-3976. [CrossRef] [PubMed]

119. Montero, J.C.; Seoane, S.; Ocana, A.; Pandiella, A. P-Rex1 participates in Neuregulin-ErbB signal transduction and its expression correlates with patient outcome in breast cancer. Oncogene 2011, 30, 1059-1071. [CrossRef]

120. Minard, M.E.; Kim, L.S.; Price, J.E.; Gallick, G.E. The role of the guanine nucleotide exchange factor Tiam1 in cellular migration, invasion, adhesion and tumor progression. Breast Cancer Res. Treat. 2004, 84, 21-32. [CrossRef]

121. Ogorodnikov, A.; Levin, M.; Tattikota, S.; Tokalov, S.; Hoque, M.; Scherzinger, D.; Marini, F.; Poetsch, A.; Binder, H.; MacherGoppinger, S.; et al. Transcriptome $3^{\prime}$ end organization by PCF11 links alternative polyadenylation to formation and neuronal differentiation of neuroblastoma. Nat. Commun. 2018, 9, 5331. [CrossRef] [PubMed]

122. Yu, B.; Liu, X.; Cao, X.; Zhang, M.; Chang, H. Study of the expression and function of ACY1 in patients with colorectal cancer. Oncol. Lett. 2017, 13, 2459-2464. [CrossRef] [PubMed]

123. Shi, H.; Hayes, M.T.; Kirana, C.; Miller, R.J.; Keating, J.P.; Stubbs, R.S. Overexpression of aminoacylase 1 is associated with colorectal cancer progression. Hum. Pathol. 2013, 44, 1089-1097. [CrossRef] [PubMed]

124. Cook, R.M.; Franklin, W.A.; Moore, M.D.; Johnson, B.E.; Miller, Y.E. Mutational inactivation of aminoacylase-1 in a small cell lung cancer cell line. Genes Chromosomes Cancer 1998, 21, 320-325. [CrossRef]

125. Zhong, Y.; Onuki, J.; Yamasaki, T.; Ogawa, O.; Akatsuka, S.; Toyokuni, S. Genome-wide analysis identifies a tumor suppressor role for aminoacylase 1 in iron-induced rat renal cell carcinoma. Carcinogenesis 2009, 30, 158-164. [CrossRef] [PubMed]

126. Wei, X.; Li, J.; Xie, H.; Ling, Q.; Wang, J.; Lu, D.; Zhou, L.; Xu, X.; Zheng, S. Proteomics-based identification of the tumor suppressor role of aminoacylase 1 in hepatocellular carcinoma. Cancer Lett. 2014, 351, 117-125. [CrossRef]

127. Lee, S.U.; Kim, B.T.; Min, Y.K.; Kim, S.H. Protein profiling and transcript expression levels of heat shock proteins in 17betaestradiol-treated human MCF7 breast cancer cells. Cell Biol. Int. 2006, 30, 983-991. [CrossRef] [PubMed]

128. Mamoor, S. ITGAL Is Differentially Expressed in Lymph Node Metastasis in Human Breast Cancer. OSF Prepr. 2021.

129. Bersini, S.; Lytle, N.K.; Schulte, R.; Huang, L.; Wahl, G.M.; Hetzer, M.W. Nup93 regulates breast tumor growth by modulating cell proliferation and actin cytoskeleton remodeling. Life Sci. Alliance 2020, 3, e201900623. [CrossRef]

130. Nataraj, N.; Noronha, A.; Lee, J.; Ghosh, S.; Raju, H.R.M.; Sekar, A.; Zuckerman, B.; Lindzen, M.; Srivastava, S.; Selitrennik, M. Nucleoporin-93 Overexpression Overcomes Multiple Nucleocytoplsamic Trafficking Bottlenecks to Permit Robust Metastasis; 2020.

131. Hsu, F.F.; Chou, Y.T.; Chiang, M.T.; Li, F.A.; Yeh, C.T.; Lee, W.H.; Chau, L.Y. Signal peptide peptidase promotes tumor progression via facilitating FKBP8 degradation. Oncogene 2019, 38, 1688-1701. [CrossRef] [PubMed]

132. Ravipati, A.S.; Zhang, L.; Koyyalamudi, S.R.; Jeong, S.C.; Reddy, N.; Bartlett, J.; Smith, P.T.; Shanmugam, K.; Munch, G.; $\mathrm{Wu}, \mathrm{M} . J . ;$ et al. Antioxidant and anti-inflammatory activities of selected Chinese medicinal plants and their relation with antioxidant content. BMC Complement. Altern. Med. 2012, 12, 173. [CrossRef]

133. Ahmed, S.A.; Gogal, R.M.; Walsh, J.E. A new rapid and simple non-radioactive assay to monitor and determine the proliferation of lymphocytes: An alternative to [3H]thymidine incorporation assay. J. Immunol. Methods 1994, 170, 211-224. [CrossRef]

134. Bhuyan, D.J.; Alsherbiny, M.A.; Low, M.N.; Zhou, X.; Kaur, K.; Li, G.; Li, C.G. Broad-spectrum pharmacological activity of Australian propolis and metabolomic-driven identification of marker metabolites of propolis samples from three continents. Food Funct. 2021, 12, 2498-2519. [CrossRef]

135. Chou, T.C. Drug combination studies and their synergy quantification using the Chou-Talalay method. Cancer Res. 2010, 70, 440-446. [CrossRef] [PubMed]

136. Chou, T.; Martin, N. CompuSyn for Drug Combinations: PC Software and User's Guide: A Computer Program. for Quantitation of Synergism and Antagonism in Drug Combinations, and the Determination of IC50 and ED50 and LD50 Values; ComboSyn: Paramus, NJ, USA, 2005. 
137. Chou, T.-C.; Martin, N. The mass-action law-based new computer software, CompuSyn, for automated simulation of synergism and antagonism in drug combination studies. Exp. Mol. Ther. 2007.

138. Kumar, R.; Saneja, A.; Panda, A.K. An Annexin V-FITC_Propidium Iodide-Based Method for Detecting Apoptosis in a Non-Small Cell Lung Cancer Cell Line. In Lung Cancer: Methods and Protocols; Santiago-Cardona, P.G., Ed.; Springer US: New York, NY, USA, 2021; pp. 213-223.

139. Wadkins, R.M.; Jovin, T.M. Actinomycin D and 7-aminoactinomycin D binding to single-stranded DNA. Biochemistry 1991, 30, 9469-9478. [CrossRef] [PubMed]

140. Schmit, T.; Klomp, M.; Khan, M.N. An Overview of Flow Cytometry: Its Principles and Applications in Allergic Disease Research. Methods Mol. Biol. 2021, 2223, 169-182. [CrossRef] [PubMed]

141. Perez-Riverol, Y.; Csordas, A.; Bai, J.; Bernal-Llinares, M.; Hewapathirana, S.; Kundu, D.J.; Inuganti, A.; Griss, J.; Mayer, G.; Eisenacher, M.; et al. The PRIDE database and related tools and resources in 2019: Improving support for quantification data. Nucleic Acids Res. 2019, 47, D442-D450. [CrossRef] [PubMed] 